
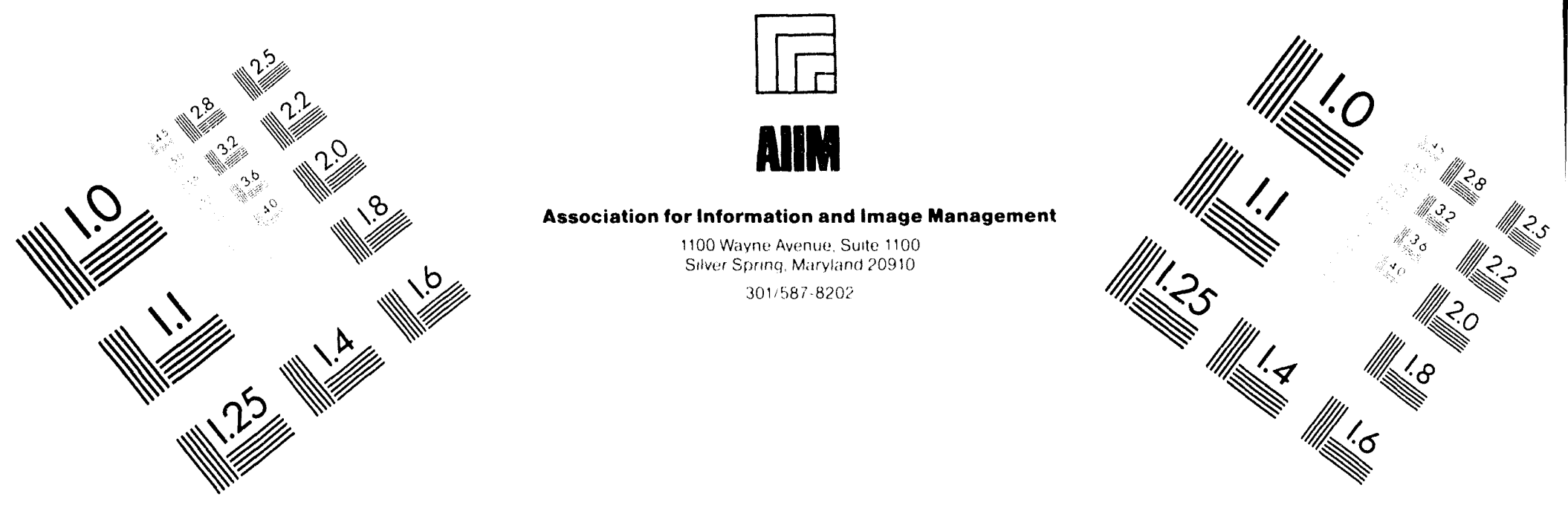

\title{
Centimeter
}

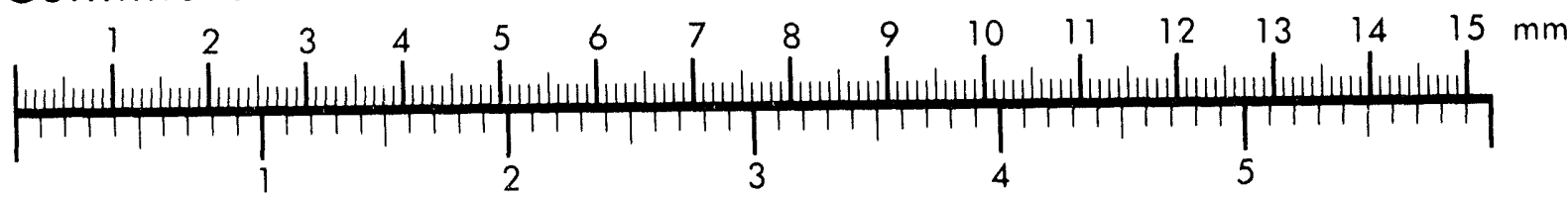

Inches
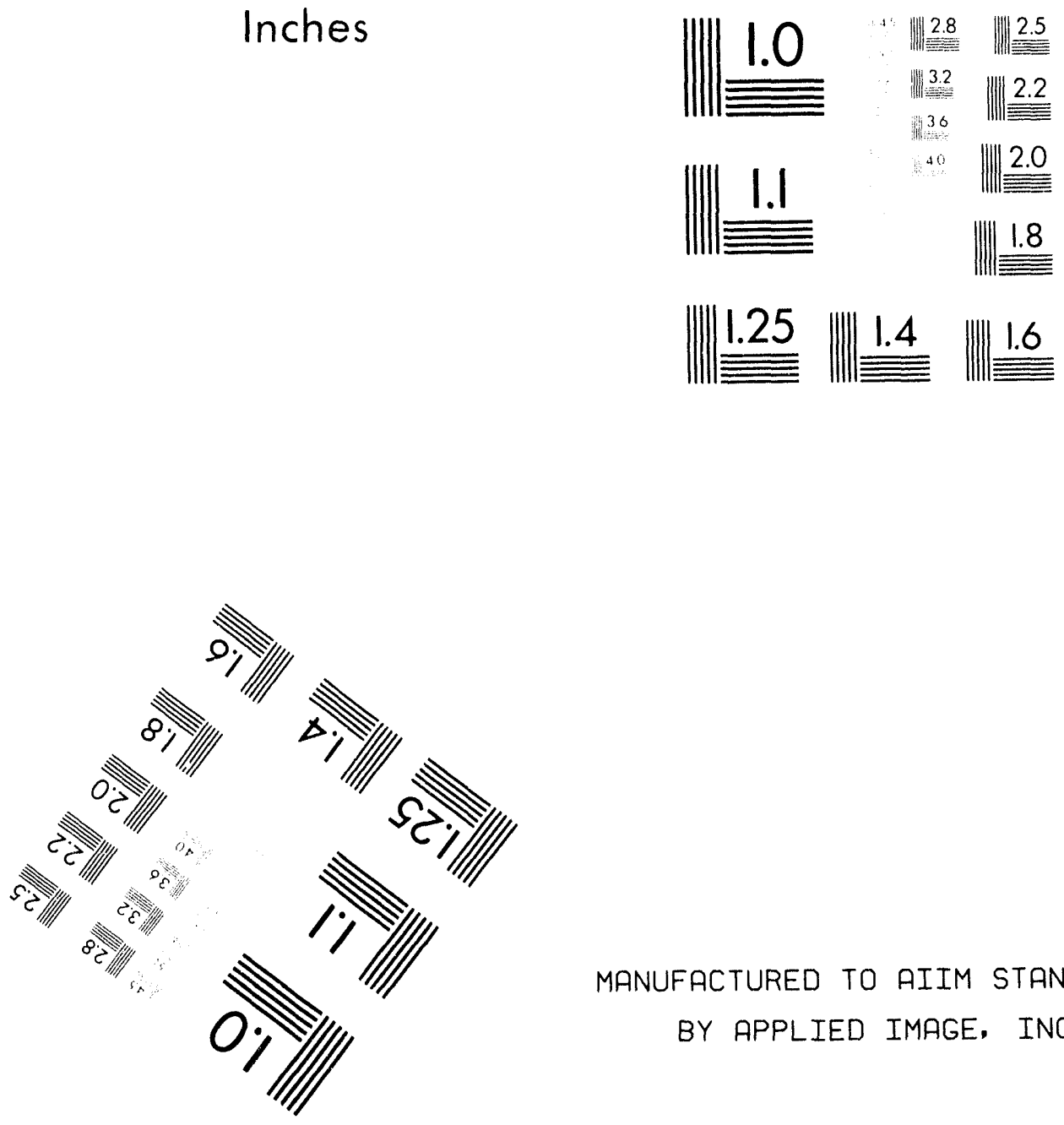

MANUFACTURED TO AIIM STANDARDS BY APPLIED IMAGE, INC.

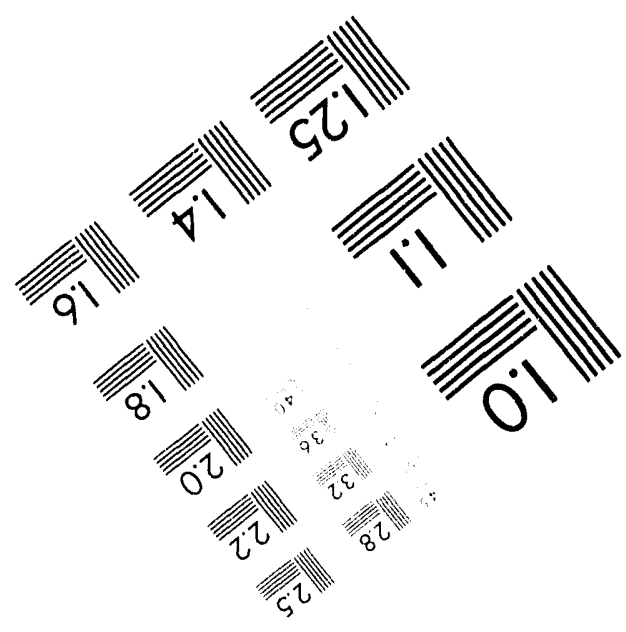



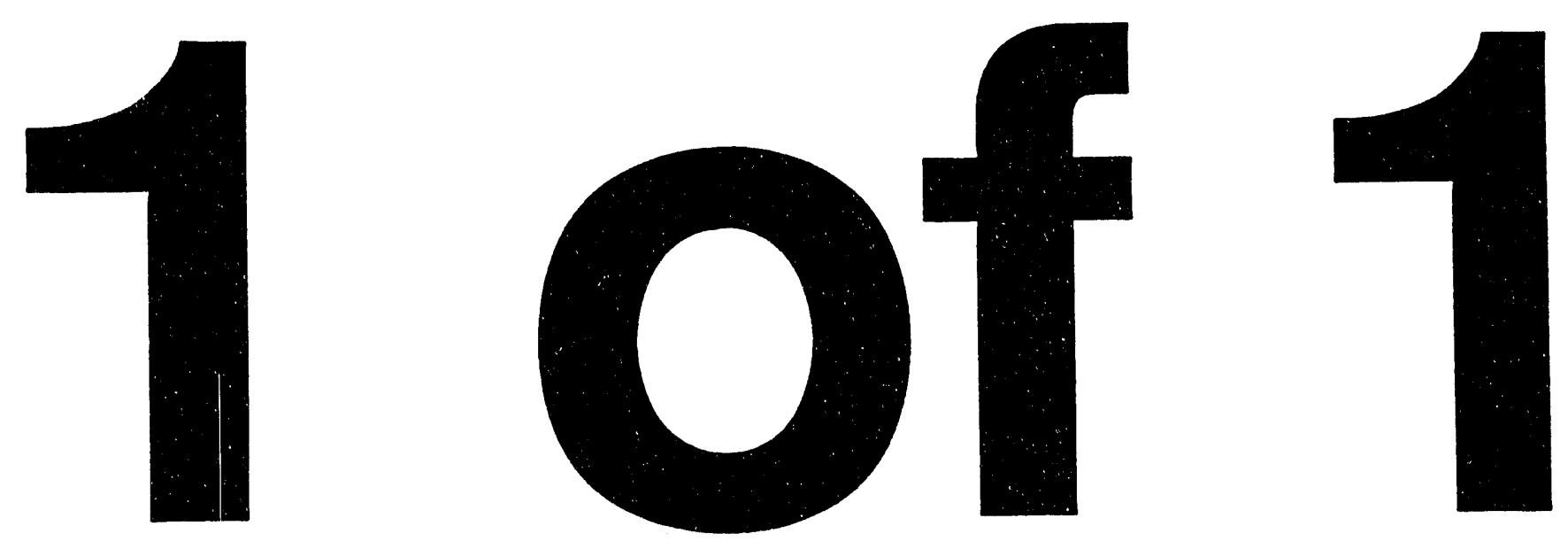

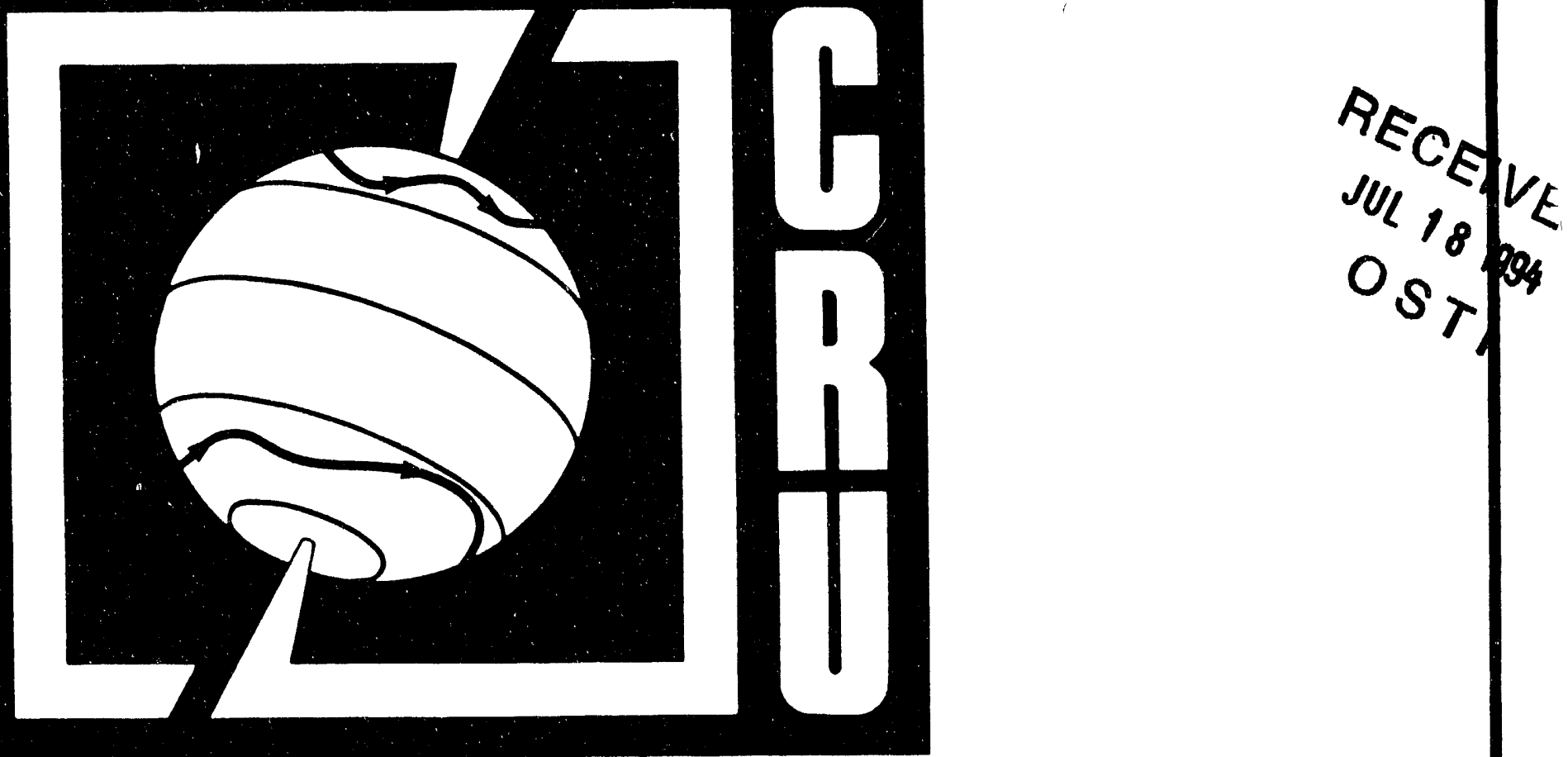

DETECTION OF GREENHOUSE-GAS-INDUCED CLIMATIC CHANGE

Progress Report to the U.S. Department of Energy

(1 December 1991-30 June 1994)

Grant No. DE-FG02-86-ER60397-A009

42

T.M.L. Wigley and P.D. Jones

1 Ju1y 1994

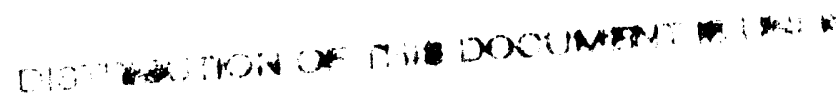

CLIMATIC RESEARCH UNIT School of Environmental Sciences

University of East Anglia

Norwich, NR4 7TJ 
DETECTION OF GREENHOUSE-GAS-INDUCED CLIMATIC CHANGE

(Grant No. DE-FG02-86ER60397-A009)

Progress Report covering the period

1 December 1991-30 June 1994

T.M.L. Wigley

and

P.D. Jones

Climatic Research Unit, School of Environmental Sciences, University of East Anglia, Norwich NR4 7TJ, U.K.

1 July 1994 
1. Project specifications 2

2. Introduction 3

3. Outline and summary of proposed research 4

4. Publications arising to date 5

5. Progress 11

A. Global climate data 11

B. Multivariate detection methods $\quad 18$

C. Transient response studies $\quad 22$

D. GCM validation $\quad 34$

E. References $\quad 38$

6. Appendices

A. Recent global warmth moderated by the effects of the Mount Pinatubo eruption. (Kelly et al., In Proceedings of the 18th Climate Diagnostics Workshop, 1994.)

B. Recent warming in global temperature series. (Jones, Geophysical Research Letters, in press.)

C. Correlation methods in fingerprint detection studies. (Santer et al., Climate Dynamics, 1993.)

D. Balancing the carbon budget. Implications for projections of future carbon dioxide concentration changes. (Wigley, Tellus, 1993.)

E. A simple model for estimating methane concentration and lifetime variations. (Osborn and Wigley, Climate Dynamics, 1994.)

F. Implications for climate and sea level of revised IPCC emissions scenarios. (Wigley and Raper, Nature, 1992.)

G. Sulfate aerosol and climatic change. (Charlson and Wigley, Scientific American, 1994.) 


\section{PROJECI SPECIFIGATIONS}

Title:

Detection of Greenhouse-Gas-Induced Climatic Change

Area :

Atmospheric and Climate Research Division, Global Change Program.

Principal Investigator:

T.M.L. Wigley

Organization:

Climatic Research Unit, University of East Anglia (UEA).

Budget :

$1991 / 92168 \mathrm{~K}, 1992 / 93176 \mathrm{~K}, 1993 / 94183 \mathrm{~K}$.

Objective: To assemble and analyse instrumental climate data and to develop and apply climate models as a basis for (1) detecting greenhouse-gas-induced climatic change, and (2) validation of General Circulation Models.

Product: In addition to changes due to variations in greenhouse gas concentrations, the global climate system exhibits a high degree of internally-generated and externally-forced natural variability. To detect the enhanced greenhouse effect, its signal must be isolated from the "noise" of this natural climatic variability. A high quality, spatially extensive data base is required to define the noise and its spatial characteristics. To facilitate this, available land and marine data bases will be updated and expanded. The data will be analysed to determine the potential effects on climate of greenhouse gas concentration changes and other factors. Analyses will be guided by a variety of models, from simple energy balance climate models to ocean General Circulation Models. These analyses are oriented towards obtaining early evidence of greenhouse-gas-induced climatic change that would lead either to confirmation, rejection or modification of model projections, and towards the statistical validation of General Circulation Model control runs and perturbation experiments.

Approach: Global surface climate data bases will be expanded and updated using the extensive resources available to the Climatic Research Unit. Data analyses will focus on the use and development of appropriate statistical techniques for signal detection and pattern recognition. Interpretations will be guided by appropriate climate models.

Deliverables: Estimates of global- and hemispheric-mean near-surface temperature, based on land and marine data will be made on a monthly basis. The following new gridded datasets will be produced: a revised, upgraded temperature data set using 1961-90 as a reference period; a "best possible", near-global mean-sea-level pressure data set; and a reference land precipitation data set spanning 1951-80, specifically for model validation purposes.

\section{Program Coordination:}

- Estimates of greenhouse-gas concentration changes during the last 200 years.

- Carbon cycle modeling (Scripps, IOS, Univ. New Hampshire, GFDL, and others).

- Model estimates of the climatic response to external forcing agents l.acluding $\mathrm{SO}_{2}$ (LLNL).

- Model estimates of the regional and global climatic response to increasing greenhouse gas concentrations (all modeling groups).

- Global precipitation analyses (Univ. Massachusetts).

- Climate data compilation and dissemination (CDIAC). 


\section{INTRODUCTION}

The aims of the U.S. Department of Energy's Carbon Dioxide Research Program are to improve assessments of greenhouse-gas-induced climatic change and to define and reduce uncertainties through selected research. Four major questisons can be identified.

(1) What are the regional and seasonal details of the expected climatic changes?

(2) How rapidly will these changes occur?

(3) How and when will the climatic effects of $\mathrm{CO}_{2}$ and other greenhouse gases be first detected?

(4) Natural variability - what are the relationships between greenhouse-gas climatic change and changes caused by other external and internal factors?

The present project addresses all of these questions.

Many of the diverse facets of greenhouse-gas-related climate research can be grouped under three interlinked subject areas:

(a) Modeling. This involves the development, validation and use of climate models of different types to estimate the details of climatic change due to increasing greenhouse gas concentrations. Transient response aspects (i.e., modeling the time-dependent response to realistic time-dependent changes in greenhouse-gas forcing) are considered to be particularly important.

(b) First Detection. The most direct form of model validation is to be able to identify, in the observational record, the modelpredicted, evolving signal of greenhouse-gas-induced climatic change. This is the detection problem. Detection research includes better defining the enhanced greenhouse signal, the signals of climatic change resulting from other forcing factors, and the characteristics of natural climatic variability. Such information is central to determining how and when the enhanced greenhouse effect can be detected with a high level of confidence.

(c) Supporting Data. The compilation and homogenization of past instrumental and paleoclimatic data is essential to support activities in areas (a) and (b). Past data are required to elucidate the mechanisms and causes of climatic changa, to define the range of past variations, to docunent possible analogs for future greenhouse-gas-induced climatic change, and to aid in model development and validation.

The main research areas covered by this project are (b), First Detection and (c) Supporting Data. The project will also include work under area (a), Modeling: specifically, analysis of climate forcing factors, the development and refinement of transient response climate models, and the use of instrumental data in validating General

Circulation Models (GCMs). 


\section{OUTLINE AND SUMMARY OF THE PROPOSED RESEARCH}

This project continued research work carried out in previous contracts in four main areas:

A. Global climate data. Updating, improvement and analysis of our global (land and marine) temperature data set.

B. Multivariate detection methods. The further development and use of multivariate techniques for the detection of both greenhousegas-induced and $\mathrm{SO}_{2}$-related climatic change.

C. Transient response studies. The use of both simple and more complex transient-response climate models in order to throw further light on the natural variability of the climate system and the possible effects of $\mathrm{SO}_{2}$-related forcing.

D. GCM validation. Validation of General Circulation Models using a variety of test statistics.

The way these items contribute to the major questions addressed by the Department of Energy's Carbon Dioxide Program (see Section 2 above) is summarized in the following Table.

\begin{tabular}{lllll}
\hline \multicolumn{1}{c}{$\begin{array}{l}\text { Project } \\
\text { elements }\end{array}$} & $\begin{array}{l}\text { Global } \\
\text { climate } \\
\text { data (A) }\end{array}$ & $\begin{array}{l}\text { Multivariate } \\
\text { detection } \\
\text { methods (B) } \\
\text { questions }\end{array}$ & $\begin{array}{l}\text { Transient } \\
\text { response } \\
\text { studies (C) }\end{array}$ & $\begin{array}{l}\text { GCM } \\
\text { validation (D) }\end{array}$ \\
\hline $\begin{array}{l}\text { Details } \\
\text { of future } \\
\text { changes (1) }\end{array}$ & & $\mathrm{X}$ \\
$\begin{array}{l}\text { Rapidity } \\
\text { of future } \\
\text { changes (2) }\end{array}$ & & $\mathrm{X}$ & \\
$\begin{array}{l}\text { First } \\
\text { detection } \\
\text { of effects (3) }\end{array}$ & $\mathrm{X}$ & $\mathrm{X}$ & $\mathrm{X}$ \\
$\begin{array}{l}\text { Natural } \\
\text { variability (4) }\end{array}$ & $\mathrm{X}$ & $\mathrm{X}$ & \\
\end{tabular}




\section{PUBLICATIONS ARISING TO DATE}

Summary

Over the 3-year period 60 scientific papers were produced that were either fully or partially supported by the project. These papers are listed below under the main aims of the project. The numbers of the references are keyed to the principal section of the progress report to which they relate.

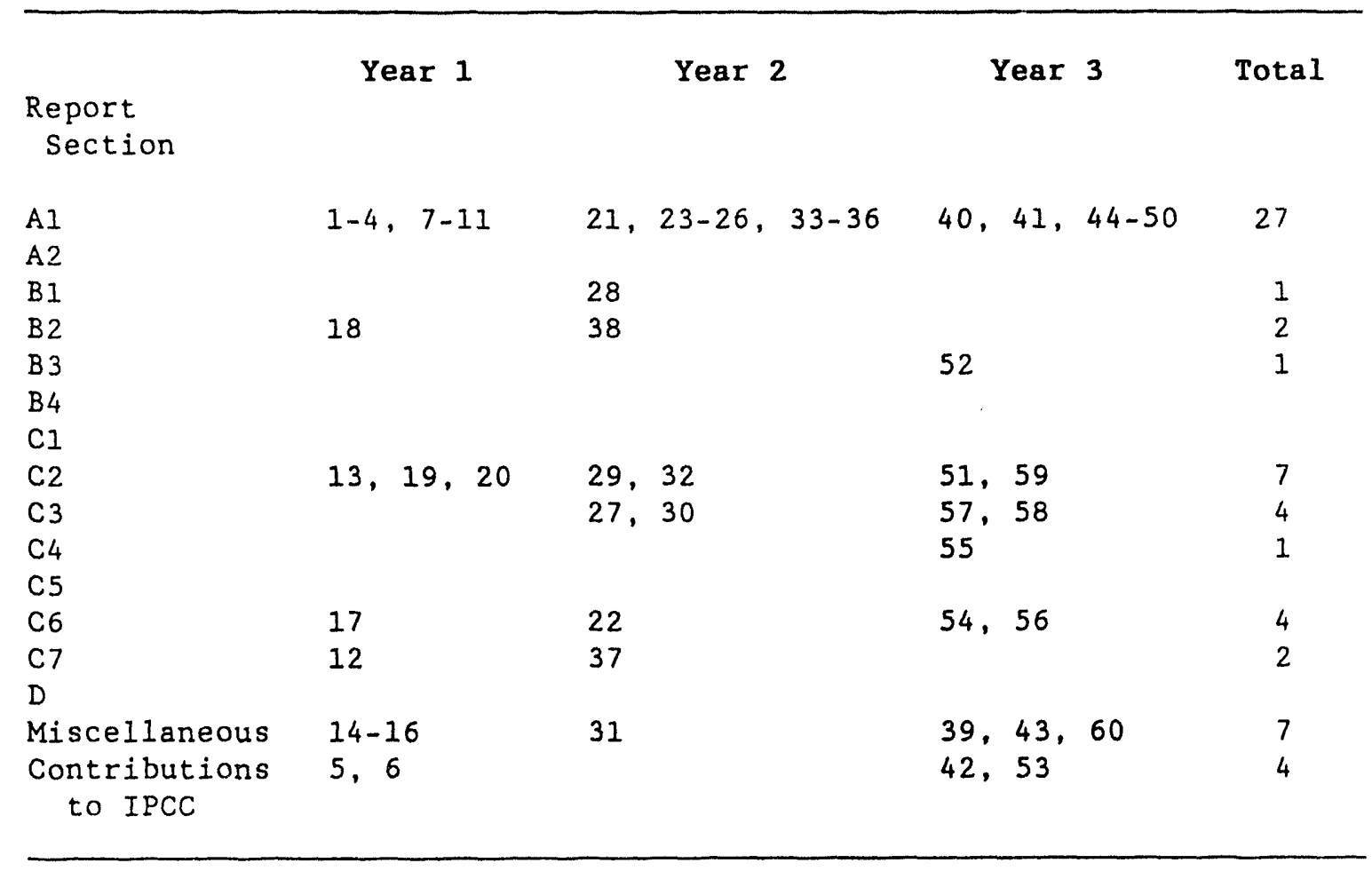

Publications produced during year-1 (1991/92) of present project

1. Bradley, R.S. and Jones, P.D., 1992: When was the Little Ice Age? In Proceedings of the International Symposium on the Little Ice Age Climate (T. Mikami, Ed.), Dept. of Geography, Tokyo Metropolitan University, $1-4$.

2. Bradley, R.S. and Jones, P.D., 1992: Climate since A.D. 1500: Introduction. In Climate Since A.D. 1500 (R.S. Bradley and P.D. Jones, Eds.), Routledge, London, 1-16.

3. Bradley, R.S. and Jones, P.D., 1992: Records of explosive volcanic eruptions over the last 500 years. In Climate since A.D. 1500 (R.S. Bradley and P.D. Jones, Eds.), Routledge, London, 606622 .

4. Briffa, K.R. and Jones, P.D., 1993: Global surface air temperature variations during the twentieth century. Part 2 , Implications for large-scale high-frequency paleoclimatic studies. The Holocene 3, 77-88. 
5. Folland, C.K., Karl, T.R., Nicholls, N., Nyenzi, B.S., Parker, D.E. and K.Ya. Vinnikov (contributing author list includes P.D. Jones and T.M.L. Wigley and 33 others), 1992: Observed climate variability and change. In Climate Change 1992: The supplementary report to the IPCC Scientific Assessment (J.T. Houghton, B.A. Callander and S.K. Varney, Eds.), Cambridge University Press, Cambridge, 135-170.

6. Isaksen, I.S.A., Ramaswamy, V., Rodhe, H. and Wigley, T.M.L., 1992: Radiative forcing of climate. In Climate Change 1992: The Supplementary Report to the IPCC Scientific Assessment (J.T. Houghton, B.A. Callander and S.K. Varney, Eds.), Cambridge University Press, Cambridge, 47-67.

7. Jones, P.D. and Bradley, R.S., 1992: Global-scale temperature changes during the period of instrumental records. In Proceedings of the International Symposium on the Little Ice Age Climate ( $T$. Mikami, Ed.), Dept. of Geography, Tokyo Metropolitan University, 253-259.

8. Jones, P.D. and Bradley, R.S., 1992: Climatic variations in the longest instrumental records. In Climate since A.D. 1500 (R.S. Bradley and P.D. Jones, Eds.), Routledge, London, 246-268.

9. Jones, P.D. and Bradley, R.S., 1992: Climatic variations over the last 500 years. In Climate since A.D. 1500 (R.S. Bradley and P.D. Jones, Eds.), Routledge, London, 649-666.

10. Jones, P.D. and Briffa, K.R., 1992: Global surface air temperature variations over the twentieth century: Part 1. Spatial, temporal and seasonal details. The Holocene 2, 165-179.

11. Jones, P.D., Santer, B.D. and Wigley, T.M.L., 1992: Fingerprint detection using spatial correlation techniques. In Proceedings of the Fifth International Meeting on Statistical Climatology (F.W. Zwiers, Ed.), Environment Canada, Atmospheric Environment Service, $437-444$.

12. Kelly, P.M. and Wigley, T.M.L., 1992: Solar cycle length variations, greenhouse forcing and global climate. Nature 360, $328-330$.

13. Raper, S.C.B. and Wigley, T.M.L., 1991: Short-term global mean temperature and sea level change. In Proceedings of the International [Nirex] Workshop on Future Climate Change and Radioactive Waste Disposal (C.M. Goodess and J.P. Palutikof, Eds.), University of East Anglia, Norwich, 203-213.

14. Raper, S.C.B., 1993: Observational data on the relationships between climatic change and the frequency and magnitude of severe tropical storms. In Climate and Sea Level Change: Observations, Projections and Implications (R.A. Warrick, E.M. Barrow and T.M.L. Wigley, Eds.), Cambridge University Press, Cambridge, 192-212.

15. Wigley, T.M.L., 1993: Climate change and forestry. Commonwealth Forestry Review 72, 256-264. 
16. Wigley, T.M.L., 1993: Future climate of the Mediterranean Basin with particular emphasis on changes in precipitation. In Climatic Change and the Mediterranean. Environmental and Societal Impacts of Climatic Change and sea-level rise in the Mediterranean Region (L. Jeftic, J.D. Milliman and G. Sestini, Eds.), Edward Arnold, Sevenoaks, 15-44.

17. Wigley, T.M.L., Jones, P.D., Kelly, P.M. and Hulme, M., 1992: Recent global temperature changes: Ozone and aerosol influences. In Proceedings of the Sixteenth Annual Climate Diagonostics Workshop, U.S. Dept. of Commerce, NOAA, 194-202.

18. Wigley, T.M.L., Pearman, G.I. and Kelly, P.M., 1992: Indices and indicators of climate change: Issues of detection, validation and climate sensitivity. In Confronting Climate Change. Risks, Implications and Responses (I. Mintzer, Ed.), Cambridge University Press, Cambridge, 85-96.

19. Wigley, T.M.L. and Raper, S.C.B., 1992: Implications for climate and sea level of revised IPCC emissions scenarios. Nature 357, $293-300$.

20. Wigley, T.M.L. and Raper, S.C.B., 1993: Future changes in globalmean temperature and sea level. In Climate and Sea Level Change: Observations, Projections and Implications (R.A. Warrick, E.M. Barrow and T.M.L. Wigley, Eds.), Cambridge University Press, Cambridge, 111-133.

Publications produced during year-2 (1992/93) of the present project

21. Bradley, R.S. and Jones, P.D., 1993: "Little Ice Age" summer temperature variations: their nature and relevance to recent global warming trends. The Holocene $3,367-376$.

22. Charlson, R.J. and Wigley, T.M.L., 1994: Sulfate aerosol and climate change. Scientific American 270, 28-35.

23. Hulme, M. and Jones, P.D., 1994: Global climate change in the instrumental period. Environmental Pollution 83, 23-36.

24. Jones, P.D., 1993: Is climate change occurrring? Evidence from the instrumental record. In, Agricultural Dimensions of Global Climate Change (H.M. Kaiser and T.E. Drennen, Eds.), St. Lucie Press, Delray Beach, Florida, 27-44.

25. Jones, P.D. and Lindesay, J.A., 1993: Maximum and minimum temperature trends over South Africa and the Sudan. In, Preprints, 4th International Conference on Southern Hemisphere Meteorology and Oceanography, American Meteorological Society, Boston, 359-360.

26. Karl, T.R., Jones, P.D., Knight, R.W., Kukla, G., Plumer, N., Razuvayev, V., Gallo, K.P., Lindesay, J. and Peterson, T.C., 1993: Asymmetric trends of daily maximum and minimum temperature: empirical evidence and possible causes. Bulletin of the American Meteorological Society 74, 1007-1023. 
27. Osborn, T.J. and Wigley, T.M.L., 1994: A simple model for estimating methane concentration and lifetime variations. Climate Dynamics 9, 181-193.

28. Santer, B.D., Wigley, T.M.L. and Jones, P.D., 1993: Correlation methods in fingerprint detection studies. Climate Dyamics 8, 265276 .

29. Warrick, R.A., Barrow, E.M. and Wigley, T.M.L. (Eds.), 1993: Climate and sea-level change: Observations, Projections and Implications, Cambridge University Press, $424 \mathrm{pp}$.

30. Wigley, T.M.L., 1993: Balancing the carbon budget. Implications for projections of future carbon dioxide concentration changes. Tellus 45B, 409-425.

31. Wigley, T.M.L. and Santer, B.D., 1993: Future climate of the Gulf/Caribbean Basin from atmospheric General Circulation Models. In, Climatic Change in the Intra-American Seas (G.A. Maul, Ed.) Edward Arnold, London, 31-54.

32. Wigley, T.M.L, and Raper, S.C.B., 1993: Global mean temperature and sea level projections under the 1992 IPCC emissions scenarios. In, Climate and sea-level change: Observation, Projections and Implications (R.A. Warrick, E.M. Barrow and T.M.L. Wigley, Eds.), Cambridge University Press, 401-404.

\section{Still in press}

33. Jones, P.D., 1994: Global surface temperature changes since the 1850s. In Environmental Data Problems - Institute of Mathematics and its Applications, Proceedings Volume (M. Ghil et al., Eds.). Springer-Verlag (in press).

34. Jones, P.D., 1994: Observations from the surface - projections from traditional meteorological observations. In, Future climates of the World, World Survey of Climatology (A. Henderson-Sellers, Ed.), Elsevier (in press).

35. Jones, P.D. and Briffa, K.R., 1994: Decadal-to-century timescale variability of regional and hemispheric scale temperature. In The Natural Variability of the Climate System on 10-100 Year Timescales (W.A. Sprigg, Ed.), National Academy of Sciences, Irvine, California (in press).

36. Karl, T.R., Jones, P.D., Knight, R.W., Kukla, G., Plummer, N., Razuvayev, V., Gallow, K.P., Lindesay, J., Charlson, R.J. and Peterson, T.C., 1994: A new perspective on recent global warming: asymetric trends of daily maximum and minimum temperature. In, The Natulal Variability of the Climate System on 10-100 year timescales (W.A. Sprigg, Ed.), National Academy of Sciences, Irvine, California (in press).

37. Wigley, T.M.L. and Raper, S.C.B., 1994: Modelling low-frequency climate variability: the greenhouse effect and the interpretation of paleoclimatic data. In, The Natural Variability of the Climate System on 10-100 year timescales (W.A. Sprigg, Ed.), National Academy of Sciences, Irvine, California (in press). 
38. Wigley, T.M.L., Jones, P.D. and Raper, S.C.B., 1994: Detecting and quantifying the enhanced greenhouse effect. In Oceans, Climate and Man, Proceedings of the International Conference held in Turin, 15-17th Apri.l 1991 (E. Gabetti and M. Zavatarelli, Eds.) (in press).

Publications produced during year-3 (1993/94) of the present project

39. Briffa, K.R., Jones, P.D. and Hulme, M., 1994: Summer moisture availability across Europe, 1892-1991: An analysis based on the Palmer Drought Severity Index. International Journal of Climatology $14,379-402$.

40. Jones, P.D., 1994: Maximum and minimum temperature trends in Ireland, Italy, Thailand, Turkey and Bangladesh. In Asymetric change of daily temperature range, Proceedings of the Minimax workshop (G. Kukla, T.R. Karl and M.R. Riches), Department of Energy Conference Series. Conf-9309350, 113-126.

41. Kelly, P.M., Jones, P.D., Diaz, H.F. and Wigley, T.M.L., 1994 Recent global warmth moderated by the effects of the Mount Pinatubo eruption. Proceedings of the Eighteenth Climate Diagnostics Workshop (D.R. Rodenhuis, Ed.), U.S. Dept. of Commerce, NOAA 5-8.

Accepted publications but not yet published

42. Albritton, D.A., Dexwent, R.G., Isaksen, I.S.A., La1, M. and Wuebbles, D.J. (contributing author list includes T.M.L. Wigley and 7 others): Trace gas radiative forcing indices. In Radiative Forcing of Climate Change (IPCC Working Group I Report) (in press).

43. Briffa, K.R., Jones, P.D. and Schweingruber, F.H., 1994: Summer temperatures across northern North America: regional reconstructions from 1760 using tree-ring densities. Journal of Geophsyical Research (in press).

44. Jones, P.D. ! 1994: Hemispheric surface air temperature variations: a reanalysis and an update to 1993. Journal of Climate (in press).

45. Jones, P.D., 1994: Recent warming in global temperature series. Geophysical Research Letters (in press).

46. Jones, P.D., 1994: The instrumental data record: its accuracy and use in attempts to identify the ' $\mathrm{CO}_{2}$ Signal'. In (H. von Storch and A. Navarra, Eds.). Proceedings of Autumn Teaching School on Analysis of Climate Variability. Springer-Verlag (in press).

47. Jones, P.D., 1994: Maximum and minimum temperature trends in Ireland, Italy, Thailand, Turkey and Bangladesh. Atmospheric Research (in press).

48. Jones, P.D. and Briffa, K.R., 1994: Growing season temperatures over the former Soviet Union. International Journal of Climatology (in press). 
49. Jones, P.D. and Kelly, P.M., 1994: The effect of large explosive volcanic eruptions on surface air temperature. In Large Volcanic Eruptions (G. Fiocco, Ed.) Accademia Nazionale dei Lincei (in press).

50. Parker, D.E., Jones, P.D., Bevan, A. and Folland, C.K., 1994: Interdecadal changes of surface temperature since the late 19 th century. Journal of Geophysical Research (in press).

51. Raper, S.C.B., Warrick, R.A. and Wigley, T.M.L., 1994: Global sea level rise: past and future. In Proceedings of the SCOPE Workshop on Rising Sea Level and Subsiding Coastal Areas (ed. J.D. Milliman), John Wiley and Sons, Chichester, U.K. (in press).

52. Santer, B.D., Mikola jewicz, U., Bruggemann, W., Cubasch, U., Hasse?mann, K., Hock, H., Maier-Reimer, E. and Wigley, T.M.L., 1994: Ocean variablity and its influence on the detectability of greenhouse warming signals. Journal of Geophysical Research (in press).

53. Schime1, D.S., Enting, I., Heimann, M., Wigley, T.M.L., Raynaud, D., Alves, D. and Siegenthaler, U., 1994: The carbon cycle. Iri Radiative Forcing of Climate Change (IPCC Working Group I Report) (in press).

54. Wigley, T.M.L., 1994: Outlook becoming hazier. Nature (News and Views) (in press).

55. Wigley, T.M.L., 1994: Global-mean sea level consequences of greenhouse gas concentration stabilization. Geophysical Research Letters (in press).

56. Wigley, T.M.L., 1994: The contribution from emissions of different gases to the enhanced greenhouse effect. In The Rio Convention on Climate Change: The New Regime and the Agenda for Research (ed. T. Hanisch), Westview Press (in press).

3i. Wigley, T.M.L., 1994: How important are carbon cycle model uncertainties? In The Rio Convention on Climste Snange: The New Regime and the Agenda for Research (Ed. T. Hanisch), Westview Press (in press).

Submitted papers

58. Hulme, M., Raper, S.C.B. and Wigley, T.M.L. (1994): An integrated framework to address climate change (ESCAPE) and further developments of the global and regional climate modules (MAGICC). In Integrative assessment of mitigation, impacts and adaptation to climate change (N. Nakicenovic and F.TOth, Eds.), IIASA Collahorative Paper Series, Laxenburg, Austria.

59. Raper, S.C.B., Briffa, K.R. and Wigley, T.M.L., 1994: Glacier change in Northern Sweden from A.D. 500: A temperature-dependent model of Storglaciaren. Journal of Glaciology (submitted).

60. Wigley, T.M.L. and Osborn, T.J., 1994: Indirect global warming potentials for methane due to $\mathrm{OH}$ feedback. Geophysical Research Letters (submitted). 


\section{PROGRESS}

The following description of progress during the three years 1 December 1991 to 1 July 1994 is keyed to the 'Summary of Aims' given in Section 3. The report covers the three years but emphasis here is on the final year along with principal findings of the first two years. Details of the first two years can be found in the two annual progress reports submitted in July 1992 and July 1993.

\section{A. Global Climate Data}

A. Hemispheric and Global Temperature

During the three years of the project we have continued to update the surface temperature data sets described earlier (see, for example, Jones and Briffa, 1992 and Briffa and Jones, 1993). The dataset produced as $5 \times 5^{\circ}$ anomalies from $1950-79$ is comprised of land air temperature and sea surface temperature anomalies. Updates of this dataset through the end of 1993 have been made available to the Carhon Dioxide Information and Analysis Center (CDAIC) in Oak Ridge, Tennessee. Over the course of the project versions of the datset have been used by many scientists in different countries (see, for example, our own work, Schlesinger and Ramankutty, 1994, Bradley et al., 1994, and many others) and by the Intergovernmental Panel on Climate Change (IPCC, Folland et al., 1990, 1992). We expect this use to continue and both PIs are involved in the ongoing 1994 and 1995 IPCC assessments.

\section{Recent Trends}

At the end of our last full (three year) report the world had just experienced its warmest recorded year in 1990. The average global temperature for that year was $0.39^{\circ} \mathrm{C}$ above the $1950-79$ reference period. The value for 1991 was slightly cooler at $0.36^{\circ} \mathrm{C}$, but still above the average value for the $1980 \mathrm{~s}$ of $0.2^{\circ} \mathrm{C}$ (with respect to $1950-79$ ). Since then temperatures have dropped to values for 1992 and 1993 of 0.18 and $0.22^{\circ} \mathrm{C}$ (see Figure 1). Even though the cooling is probably related to the explosive volcanic eruption of Mt. Pinatubo in the Philippines in June 1991 (the largest such eruption since Krakatoa in 1883) much has been written and speculated in both the scientific and popular press concerning the relevance to the 'global warming' issue. The fact that climate change resulting from anthropogenic influences is on the decadeto-century timescale, whereas volcanic and E1 Nino events produce some of the interannual variability, is frequently ignored.

We have investigated the response of the surface temperature field to the effects of the eruption in two papers (Kelly et al., 1994 and Jones and Kelly, 1994), although the response is confounded somewhat by the protracted ENSO phenomenon (a warm event) during 1991 to 1993. One might argue that the influence at the surface of the stratospheric dust/aerosols injected there by the volcano might have been greater but for the warm event. A number of other intriguing features of the climate response of this eruption will be partially resolved over the next few years by a combination of empirical and modelling studies. In Kelly et al. (1994) (Appendix A) we showed that the cooling at the surface was not as immediate as for some earlier eruptions this century, although the free troposphere showed evidence of cooling relatively quickly (Christy and McNider, 1994). Although the pattern of surface response in the Northern Hemisphere of individual explosive eruptions 


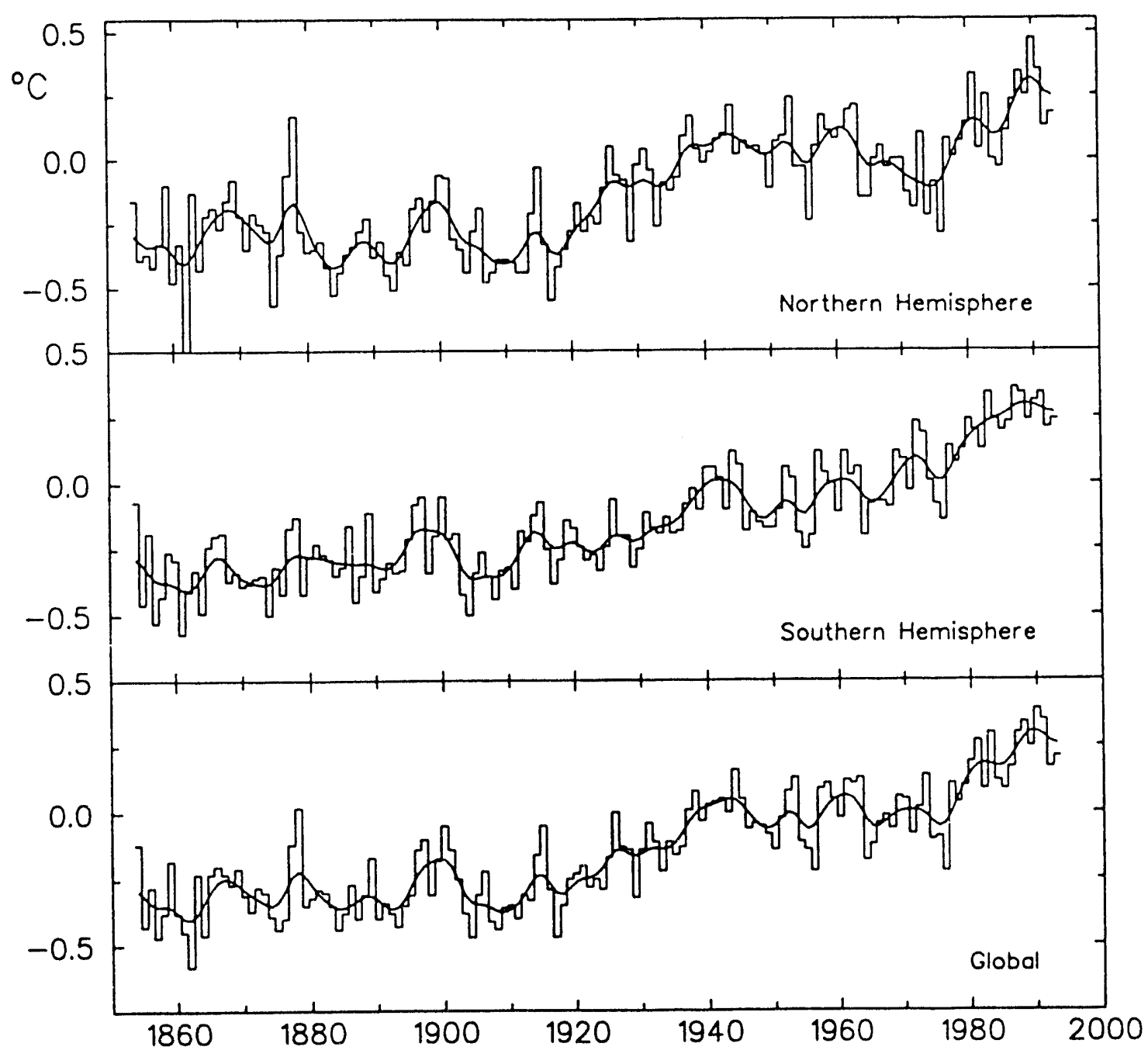

Figure 1: Northern Hemisphere, Southerm Hemisphere and Global annual surface temperature (land plus marine data), 1854-1993. Data are expressed as anomalies from 1950-1979. 
varies because of timing and location of the volcano, the response after Pinatubo showed some features of what might be termed the 'classic' volcano. The main feature of this is a cooling over the eastern half of North America during the N.H. summer half of the year immediately following the eruption (viz. April-November 1992 in this case). Other volcanoes have shown cooling over Europe at the same time but this was not evident after Pinatubo. The composite response patterns (from four earlier eruptions this century) and that of Pinatubo are given in Appendix A.

Perhaps the most intriguing aspect of the surface response has been the lack of any cooling during the December to March period in the Northern Hemisphere (see Figure 2). The average hemispheric response for the terrestrial regions clearly shows relative peaks during these months. Some modelling results (Graf et al., 1993) also show this feature. Further studies are clearly required in this area.

The other aspect of the recent period that deserves some discussion relates to the differences between surface and tropospheric (piinripally those based on microwave sounding units (MSU2R) on NOAA polar orbiting satellites) estimates of hemispheric and global temperatures. Several intercomparisons of the two data sets over the period of availability of the MSU2R (1979 to the present) have been undertaken (Folland et al., 1990, 1993; Trenberth et al., 1992 and Jones and Wigley, 1990). All conclude that the two are in best agreement at the largest of spatial scales. At smaller spatial scales the agreement is poorer, particularly over the tropical regions away from the eastern equatorial Pacific. Even at the global scale the agreement is not perfect, such that extreme warm years in one analysis aren't necessarily the warmest years in the other. Interannual and seasonal correlations between MSU2R at the hemispheric and global scale are, however, as high as correlations between the surface and the conventional radiosonde network (Angell, 1988) (see, for example, Jones, 1994a).

Much of the discussion concerning the differences between the datasets relates to the minimal trend in the MSU2R data over 1979 to 1993. Over this 15-year period the surface shows a slight warming and the MSU2R and the conventional radiosonde network both show a slight cooling. Neither the warming nor the cooling trend is statistically significant - nor is the difference between the two (Jones, 1994a). The lack of significance is principally due to the inherent interannual variability in both datasets, larger in the troposphere compared to the surface. Interpreting the trends in such short datasets is confounded by volcanic and ENSO events occurring at the ends of the short record.

In this regard the recent paper by Christy and McNider (1994) is important because they attempt to reduce these end effects by extracting "two of the main causes" of interannual variability over this period, the ENSO phenomenon ( 4 El Nino and 1 La Nina events) and two explosive volcanic eruptions (E1 Chichon in April 1982 and Mt. Pinatubo in June 1991). Once the influence of these short timescale events has been extracted the MSU2R data shows a warming of $0.09^{\circ} \mathrm{C}$ per decade over the 15 year period. Jones (1994b) has extended the analysis to show similar results for the surfa?e data over the 15 years, and for longer periods back to 1958 using both the radiosonde network (Angell, 1988) and the surface data (see Appendix B). The surface data since 1979 shows a warming (after extracting the two influences) of $0.17^{\circ} \mathrm{C}$ per decade. Over the longer time interval of 36 years the radiosonde network and the surface (both after extraction) warm by $0.11^{\circ} \mathrm{C}$ and $0.10^{\circ} \mathrm{C}$ per decade. 


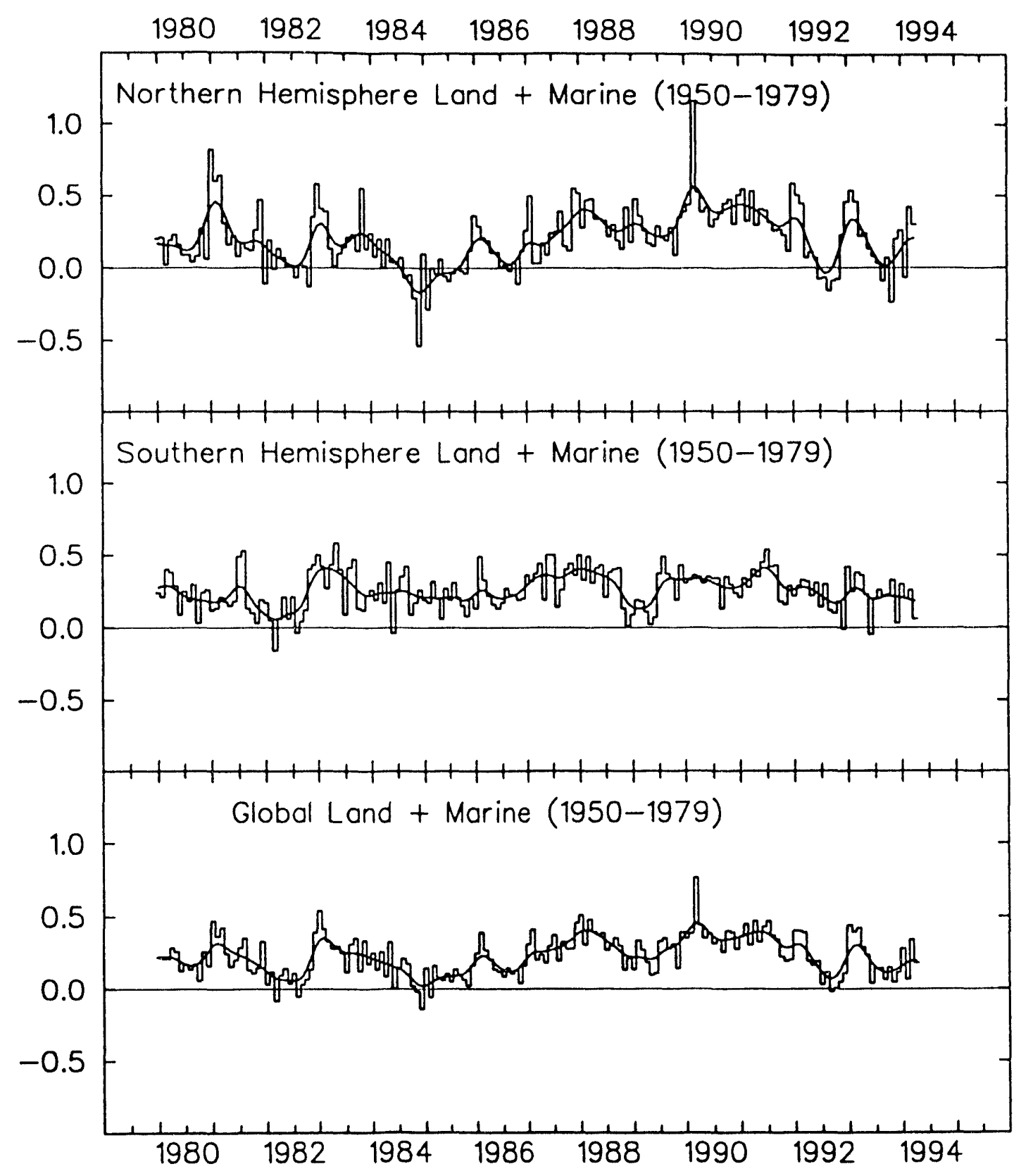

Figure 2: Monthly estimates of hemispheric- and global-mean combined (land and marine) temperatures for the 1980 to April 1994 period. Data are expressed as anomalies from the 1950-1979 period. 
These values of the trend are in agreement with that suggested by models which include the effects of the past greenhouse gas concentration changes, stratospheric ozone depletion effects and sulphate aerosols (see Table 1).

Table 1: Updated estimates of anthropogenic warming trends ( ${ }^{\circ} \mathrm{C} /$ decade) allowing for latest estimates of past greenhouse gas concentration changes, stratospheric ozone depletion effects, sulphate aerosols (best guess from Wigley and Raper, 1992), and oceanic thermal inertia $\left(\Delta T_{2 x}\right.$ as given, $\mathrm{h}=90 \mathrm{~m}, \pi=0.2, \mathrm{~W}=4 \mathrm{~m} / \mathrm{yr}, \mathrm{K}=1 \mathrm{~cm}^{2} / \mathrm{sec}$; Wigley/Raper upwelling diffusion model)

\begin{tabular}{|c|c|c|c|}
\hline Decade ${ }^{\Delta T_{2 x}\left({ }^{\circ} \mathrm{C}\right)}$ & 1.5 & 2.5 & 4.5 \\
\hline $1960 \mathrm{~s}$ & 0.002 & 0.005 & 0.013 \\
\hline $1970 \mathrm{~s}$ & 0.054 & 0.070 & 0.090 \\
\hline $1980 \mathrm{~s}$ & 0.089 & 0.122 & 0.164 \\
\hline
\end{tabular}

Longer-period analyses

In conjunction with the Hadley Centre of the U.K. Meteorological office we have extended the analysis of the surface temperature record since the mid-nineteenth century by IPCC (Folland et al.. 1990, 1992). Parker et al. (1994) (in which PDJ was involved) show decade maps since the 1880 s and they discuss further the combination of the land and marine temperature data bases and the inherent sampling errors, both at the grid-box and the larger-scale level.

Over the last few years PDJ has also assisted Dr Jim Salinger of the National Institute for Water and the Atmosphere (NIWA) in New Zealand in the search for long temperature records in the southwestern Pacific and the assessment of their homogenity. Many early twentieth and late nineteenth century records for the region are held in Britain. A paper has been written and accepted (Salinger et al., 1994) on their analysis, particularly with regard to the relationships between regional temperatures and the ENSO phenomenon.

Another area of recent work has been the study of changes and trends in maximum and minimum temperatures. Special efforts have been made to digitise and collect such data, as averages of the two daily extremes are not routinely exchanged (as is the case with mean temperatures). This situation should change in November 1994 when the World Meteorological Organization (WMO) alters its codes and the data are exchanged over the CLIMAT network.

Analyses of data from stations comprising 372 of the global land area (Karl et al., 1993) indicate that three quarters of the rise in temperature between 1951 and 1990 has occurred at night (minimum) with only one quarter coming from daytime (maximum) temperatures. The reduction in the diurnal range is therefore equal to the rise in temperature over this time. The reduction in the range is thought to be due to cloudiness changes, although how much is just a natural effect is unknown. 
The implications for the potential impacts of climate change, if such a trend were to continue, are large. PDJ attended the MINIMAX workshop in College Park, Md in September, 1993 where the issue was addressed from the empirical, modelling, impact and response areas. paper presented (Jones, 1994c) shows the differing nature of the response of maximum and minimum temperatures to cloudiness changes in five countries, Italy, Ireland, Bangladesh, Turkey and Thailand. Cloudiness data are particuarly important in the whole 'global warming' debate, but few countries have good homogeneous time series - the data being severely affected by observational method changes and observer biases. A new atlas of cloudiness changes produced with Department of Energy support by Hahn et al. (1994) will be of consicierable use here.

\section{Gridded Temperature Analyses}

The major piece of work in this area has been a reanalysis of the land station air temperature data. The principal reason for undertaking this was to increase the number of stations entering the analysis. In the earlier analysis (Jones et al., 1986a, 1986b), the number of useable stations reporting over the CLIMAT network reduced from about 1200 to 900 during the 1980s. The reduction is partly due to inadequacies in the network, but also to stations closing and political conflicts. In a number of developing regions, particularly the tropics, the CLIMAT network contains stations which do not have sufficient years of data in the old 1951-70 reference period to allow their use in the analysis. In the new analysis, the reference period was changed to 1961-90 (i.e., the new WMO reference period). Also, the method of interpolating the station anomaly data was modified. Some countries have issued 'normal' values for this new reference period. In some areas these normals are important as data for some years are missing from publications such as Monthly Climatic Data for the World. It is also relatively easy to include many of the stations for which the maximum and minimum temperatures have been collected (through the Karl et al., 1993 work) though many of these stations do not report in real time.

The new method (Jones, 1994b) estimates temperature anomalies for each $5 \times 5^{\circ}$ box, each station only contributing to the box in which it is located. The use of boxes rather than a grid point value will make later combination with marine data considerably easier. The method will also enable the incorporation of additional data, once these become available, to be achieved without the need for a complete regridding.

The results of the new analysis differ little from the earlier analyses at the hemispheric and global scales, as would be expected. The greatest differences occur when the 1961-90 reference period is much warmer or cooler than that of 1951-70. Even then the change is mainly manifest as a change of level. The differences are relatively subtle and are only really of interest when comparisons between the two datasets are made at the local scale. The differences relate to the small number of stations in the earliest years and the differences in temperature between the two reference periods.

A2. Mean-sea-level pressure (MSLP)

During the course of the present contract period, we have only attempted to update our Southern Hemisphere grid reconstructions (Jones and Wigley, 1988; Jones, 1991). Although this only constitutes updating 
monthly data for 87 sites in the Southern Hemisphere for 1986-1993, the work is particularly time consuming. Apart fro.n stations operated by Australia, New Zealand and South Africa, the majority only have 50-75\% of months with data in publications such as Monthly Climatic Data for the World. The updating is nearly complete and the results will be made available to a few scientists in South America, Australia and New Zealand.

In our proposal we said that we hoped to develop a homogeneous gridded MSLP dataset for the Northern Hemisphere (back to 1873) and for the Southern Hemisphere (back to 1972). We learnt early in year 2 that this task was being undertaken by the Hadley Centre of the UK Meteorological office and by the Division of Atmospheric Research (DAR) at CSIRO, Aspendale, Australia. We are working in collaboration with both institutes and all our data is being incorporated into their efforts. DAR are hopeful of exteriding the $\mathrm{SH}$ reconstructions back to the 1910s. The resulting dataset will be particularly aseful for validation of modelling efforts that seek to understand the causes of twentieth century climatic change. 


\section{B. Multivariate Netection Methods}

In our original proposal we planned to extend ongoing work in four areas, viz.

(1) Testing with simulated data.

(2) Application to other model data.

(3) Application to other spatial fields.

(4) Application to other signals.

We have made significant progress in three of these areas (1, 2 and 4$)$.

First, we further developed the pattern correlation technique introduced by Barnett (1986) and Barnett and Schlesinger (1987) and applied this to detection of the effects of $\mathrm{CO}_{2}$ on the patterns of nearsurface temperature change. The results are published in Santer et 91 . (1993) (Appendix C). The main theoretical advance of this work was to show the normalization of the grid-point temperature changes by the local temporal standard deviation (as suggested in the above-cited Barnett papers) leads to spurious trends due to a "common factor effect". We also showed that Barnett's uncentered cross-moment statistic, $C(t)$, may be split into a term proportional to the areaaverage and a term proportional to the centred statistic, $R(t)$ :

$$
C(t)=a R(t)+b \overline{\Delta D}(t)
$$

For the $\mathrm{CO}_{2}$-alone signal, $a R(t) \ll b \overline{\Delta D}(t)$, so that changes in $c(t)$ reflect only changes in the area-average and convey nothing about the underlying pattern of change.

we concluded, therefore, that the most informative detection statistic of this kind is $R(t)$, the standard product-moment correlation coe:ficient between the observed and model fields. We have used this with near-surface temperature data to try to detect the greenhouse warming signal defined by five different models. In each case, using either annual or seasonal data, we found no meaningful trends in $R(t)$.

This result can be interpreted in various ways. If we assume that the greenhouse signal patterns used are basically correct, then our failure to detect a large positive trend in $R(t)$ could be due to the fact that the signal is being obscured by the backgound noise arising from natural internal climate variability and other forcing factors (e.g., aerosols, solar variability, etc.). This, in turn, could be due to the magnitude of the noise being large, or to the signal being noticeably less than suggested by the models we have used (i.e., $\Delta T_{2 x}$ substantially less than $2.8^{\circ} \mathrm{C}$ ).

Alternatively, the signal patterns used in this $\mathrm{CO}_{2}$-alone study may be erroneous. This could be because of deficiencies in the model output we have used, which would imply major errors in existing simulations of the climate response to increased $\mathrm{CO}_{2}$, or it could be because other signals are significantly affecting climate. The most likely candidate here is the effect of aerosol forcing.

Second, in our subsequent work on this topic (carried out in collaboration with B.D. Santer, K.E. Taylor and J.E. Penner of Lawrence Livermore National Laboratory) we have extended our analysis to search for evidence of a combined $\mathrm{CO}_{2}$-aerosol signal in the observed temperature record (area 4 above). In doing this, we have also 
considered an additional $\mathrm{CO}_{2}$-alone signal from the Taylor/Penner model (area 2), and we have developed a significance test strategy using model-simulated natural variability data (area 1). This work is still on-going and the results described below are only preliminary.

The model signal data we have used is that of Taylor and Penner (1994); $\mathrm{CO}_{2}$-alone, aerosol-alone and combined $\mathrm{CO}_{2}$-aerosol experiments with a mixed-layer ocean coupled to a version of the NCAR community climate model (CCM1) AGCM. We first developed a filtering technique that allows us to make better use of the avallable observational data, improving the coverage. We then calculated annual and seasonal time series for both $C(t)$ and $R(t)$. $C(t)$ is more useful in the combined $\mathrm{CO}_{2}$ aerosol case than for $\mathrm{CO}_{2}$-alone, because the $R(t)$ and $\Delta D(t)$ terms in the above $C(t)$ breakdown are more similar in magnitude. The $R(t)$ results for the combined forcing case ara shown in Figure 3 . These results are strikingly different from those for $\mathrm{CO}_{2}$ alone. This is most pronounced in JJA and SON; both $C(t)$ and $R(t)$ now show large positive trends which are sustained over the last 40-60 years of the observed record (in fact, over the entire 1910-1993 record for $C(t)$ ). For $R(t)$, the linear trends in JJA, SON and ANN initially decrease from ca. 19101940 .

These results suggest that the inclusion of forcing by both $\mathrm{CO}_{2}$ and anthropogenic sulfate aerosols enables one to obtain a better fit between observed variations in near-surface temperature and a modelpredicted temperature response pattern, particularly over the 1940-1973 period, when $C(t)$ and $R(t)$ show little trend for the $\mathrm{CO}_{2}$-only signal. In other words, the observed data must have some time-increasing congruence with the time-independent JJA and SON signal patterns from the combined forcing experiment.

Put in simpler terms, it appears that we have detected the increasing presence of an anthropogenic climate-change signal. If our subsequent aralysis confirms this preliminary finding, and if it is also confirmed using signals derived from other models, then this is an important result.

An important step in assessing these results is to try to determine whether the $R(t)$ trends noted above are statistically significant. This is difficult because we cannot theoretically determine the sampling distribution for $R(t)$. And, even if we could, we do not have a sufficiently long observed data record with which to quantify the low-frequency characteristics of the natural variability of $R(t)$.

We therefore used surface temperature results from a 600-year control integration recently performed with a fully-coupled atmosphereocean GCM (ECHAM-1/LSG; see, e.g., Cubasch et al., 1992) in order to establish the sampling distributions of $R(t)$ (and $C(t)$ ) trends in the absence of external forcing. This integration exhibits substantial variability on decadal-to-century time scales, which has been described by Cubasch et al. (1992) and others. There are, however, still reservations regarding the fidelity with which multi-decadal variability is simulated in this experiment, so one must be cautious in accepting results based on it.

To determine the significance of the $R(t)$ and $C(t)$ trends, we first need to establish the sampling distributions of trends in these statistics in the absence of any external forcing. We treat the control run results in the same way that we treated the observed near-surface 
$R(t):$ CCM - 1 HSHC (YEARS 17-36) - LSLC (YEAR 11-30) 13-term Gaussian Filter. Anomalies relative to 1900-12 and 1948-60.

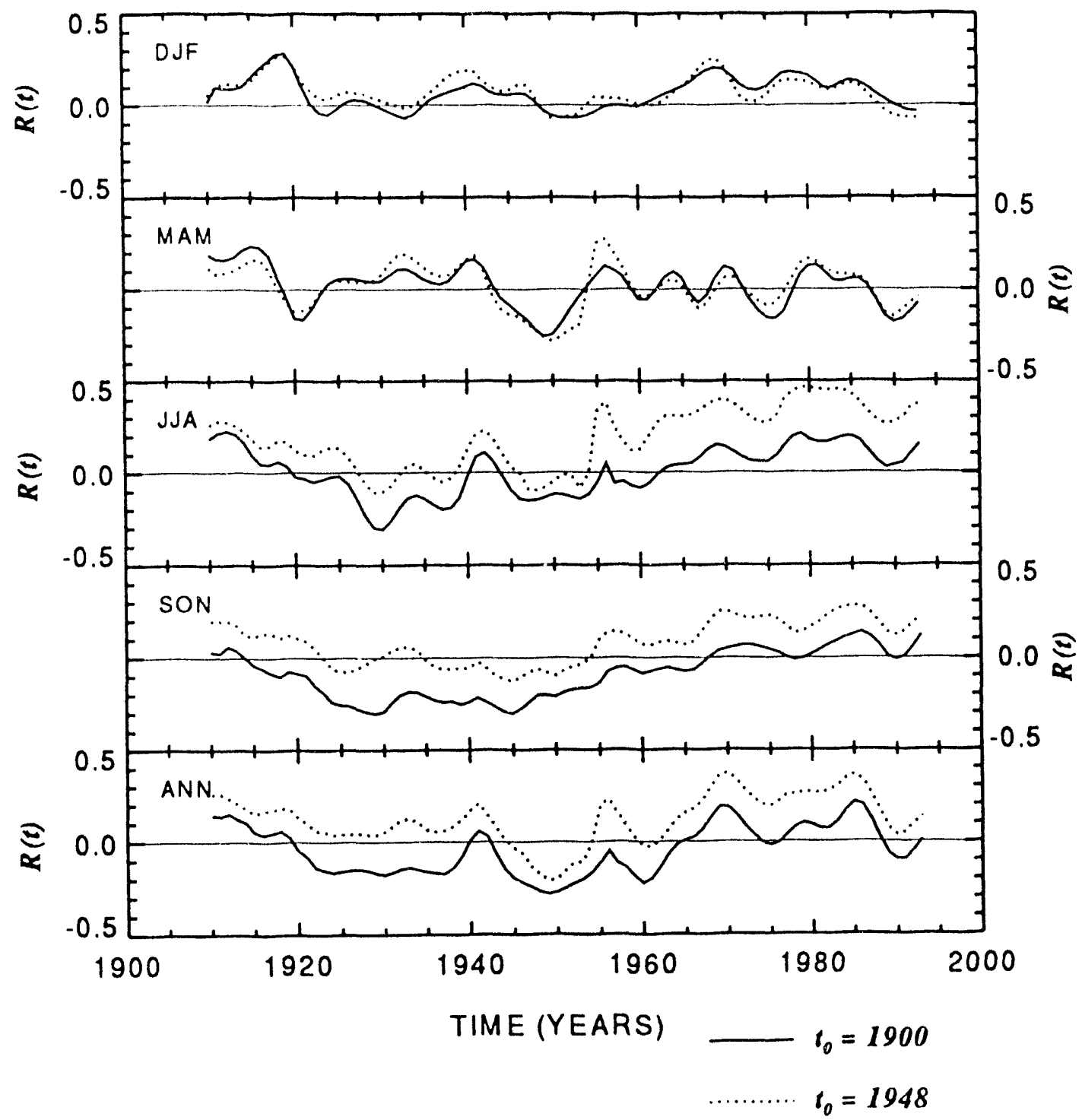

Figure 3: Pattern correlation statistic trends for near-surface temperature data compared with "high aerosol $\left(\mathrm{SO}_{2}-\right.$ high $\mathrm{CO}_{2}$ " (HSHC) climate model resuits of Taylor and Penner (1994). 
temperature data, and first define anomalies relative to some reference state. These anomalies were then interpolated onto the observed data grid omittin points with missing observed data, and these data were then used as a substitute for the observed data. Since the model control-run data have no anthropogenic signal, by definition, calculating $R(t)$ trends with these data should produce a null result. Some trends will, of course, appear $\mathrm{by}$ chance, and it is the distribution of these chance occurrences that determines the sampling distribution for $R(t)$.

In practice, we need to determine $R(t)$ sampling distributions for trends of $10,20,30$, etc. years. To do this, we divided the control run into non-overlapping $10,20,30$, etc. year intervals, and calculated $R(t)$ values for each. The sample sizes therefore range from $m_{1}=58$ for 10 -year chunks to $m_{5}=11$ for 50 -year chunks. This yields a distribution of slope parameters, for each season and response experiment. These distributions are the yardsticks which we use to judge the significance of signal trends. Preliminary results indicate that the longer-term $R(t)$ trends ( $30+$ years) in JJA and SON are highly statistically significant. 
C1. Generalization of the 1-D mode1

The transient response of climate depends critically on the climate sensitivity and on the magnitude of ocean mixing. Passive internal variability (arising from ocean thermal inertia) also depends critically on these factors. Both of these aspects of the climate system have previously been studied by using simple upwelling-diffusion (UD) energy-balance climate models. These models represent vertical mixing in the ocean by a highly simplified parameterization, usually involving just two constant parameters (vertical diffusivity and upwelling rate), plus a parameter controlling changes to the temperature of the model's deep water formation. Wigley and Raper (1987, 1990 , 1991) have performed sensitivity tests for many possible combinations of these parameters, in both the time-and frequency-domains.

We have now carried out a suite of experiments with a more generalized UD model. Both Pacanowski and Philander (1981) and Gargett (1984) suggested rarameterizations for vertical diffusivity which are dependent upon the stability of the ocean, for use in ocean general circulation models. The resulting diffusivity is both space-and timedependent. Hoffert (personal communication) has developed such a parameterization that is suitable for use in a one-dimensional UD model. Hoffert then extended this UD model to include a prognostic equation for the upwelling velocity, based on the assumption that upward momentum is input at the base of the water column, and then dissipates away as the water upwells, with the dissipation rate dependent upon the energy required to raise the water. In this generalized model, both the vertical diffusivity $(K)$ and the upwelling velocity (W) are depth-and time-dependent. In the steady-state, this model yields an improved simulation of the global-mean steady-state vertical profile of ocean temperature, compared to the constant $K$, constant $W$ model used previous1y.

Further possibilities have also been studied. The first replaces the completely mixed layer of previous UD models with a layer of higher diffusivity (Gregory, personal communication), which attempts to represent the input of turbulent kinetic energy by surface mechanical and buoyancy forcing. A new analysis of the annual mean observed ocean temperature and salinity dataset of Levitus (1982) found that the vertical component of along-isopycnal heat diffusion may be significant in the global mean (contrary to the earlier result of Hoffert and Flannery, 1985). The inclusion of an estimate of this component was also investigated. Both of these theoretical additions also made slight improvements to the steady-state simulation of the UD model.

In all, approximately 15 alternative UD models have been derived, each with different profiles of upwelling velocity and vertical diffusivity - some of which have time-dependent parameters. Investigations in the time-domain of some of these alternatives had already been done - and this was extended to cover all the models. The responses of these alternative models to the same radiative forcing scenario covered a wide range. The differences between the estimates of final sea level rise due to thermal expansion (and the rate of sea level rise) were larger than the differences between surface temperature changes.

All the UD models were also tested in the frequency-domain, by forcing them stochastically (as Wigley and Raper, 1990, 1991, did for 
the constant $K$, constant $W$ model). Again, the range of responses was quite large. When the forcing was the same (i.e., the standard deviations of the stochastic timeseries of heat flux anomalies were the same) for all UD models, then the differences were large at all but the lowest frequencies (i.e., large for all timescales <1000 years). However, if the magnitude of the forcing is adjusted individually, so that the high frequency variance of every UD model matches the observed high frequency variance, then the differences decrease (as expected) for these higher frequencies, but increase for lower frequencies (including millennium timescales, where the model responses were previously similar).

As well as being a very useful tool for comparing the UD models, the frequency-domain tests produced a range of estimates of the spectrum of passive internal variability due to ocean thermal inertia. Therefore, the uncertainty range of the magnitude of passive internal ocean variability has been better defined.

The physical process that accounts for the largest inter-model differences is the feedback between surface warming and a stabilitydependent diffusivity. In the models that include this process, the surface warming increases the vertical stability of the upper part of the water column, diffusive mixing is reduced, which restricts the downward penetration of the heat anomaly, and hence the surface warming increases compared with the standard case. The reduction in the penetration of the heat anomaly causes the layer of warming to be thinner than in the standard case, so that the sea level rise due to thermal expansion is reduced, both in the transient response and in the equilibrium state. When the surface anomalies are negative (i.e., cooler), the opposite occurs, due to a reduction in the stability and an increase in the diffusivity. If this feedback process exists in the real oceans, then sea surface temperature rise will be faster, but sea level rise slower, than the estimates obtained using the constant $k$, constant $W$ upwelling-diffusion model.

C2. Probabilistic assessment of future global-mean temperature and sea level changes.

We have carried out a probabilistic assessment of future globalmean temperature and sea level projections, concatenating the effects of uncertainty in future radiative forcing (using the results of the 1992 IPCC assessment; see Wigley and Raper, 1992) and uncertainties in model parameters. However, because of recent changes to the gas cycle models, in particular the carbon cycle model (Wigiey 1994), and proposed changes to the climate and sea level models, we consider the results as preliminary; although they are the appropriate probabilities associated with results as published in 1992.

We have carried out the analysis for each of the six IS92 forcing scenarios individually and compared these results with those produced by defining a forcing probability distribution. The latter was defined by fitting shifted log-normal distributions for each year using the IS92a scenario for the median values ( $50 z$ of occurrences lying to the left and right) and the IS92C and IS92e scenarios for the lower and upper $90 \%$ probability bounds.

Probability distributions were fitted to each of the climate and sea level model parameters; the median and $90 \%$ confidence bounds were 
defined as the best guesses and ranges as given in Table 7.3 of Wigley and Raper (1993). Where the ranges are symmetrical, normal

distributions were used, while for asymmetric ranges we fitted shifted log-normal distributions. For example, for the climate sensitivity $\left(\Delta \mathrm{T}_{2 \mathrm{x}}\right)$ we used the IPCC best guess of $2.5^{\circ} \mathrm{C}$ as the median value of a shifted log-normal distribution with lower and upper $90 z$ bounds of $1.5^{\circ} \mathrm{C}$ and $4.5^{\circ} \mathrm{C}$. The IPCC did not themselves assign a confidence limit on the range $1.5^{\circ} \mathrm{C}$ and $4.5^{\circ} \mathrm{C}$. Our assignation of this range as the $90 \%$ confidence limit is thus a subjective but well-informed guess.

The probability assessments were carried out by an exhaustive sampling procedure drawing on the standard Latin Hypercube sampling method, involving about 100,000 model runs.

Figure 4 a) shows the probability density function results for temeprature in 2100 using the individual 1592 forcing scenarios and, for comparison, Figure $4 \mathrm{~b}$ ) shows the result using the probabilistic forcing scenario.

Also using the probabilistic forcing scenario, Figure $5 a$ ) shows the probabilistic sea level change results for 2100 for the four contributing factors. The largest contributor is thermal expansion but the uncertainty is also large. If the lower warming over the ocean compared to the land, indicated by recent GCM results, proves to be correct, the contribution from this factor will be less important than indicated here. Second most important are the glaciers; we are currently reviewing these models and the indication is that this component will also decline (see below). Greenland and Antarctica together, despite their enormous ice volume, are presently expected to contribute little over the next century. In view of the anticipated changes we may expect our next set of future sea level change estimates to be revised downwards once again.

Figure 5a demonstrates the large uncertainty associated with each of the contributors to sea level rise. Thus, when these uncertainties are combined into a single probability density function the spread is very large indeed (Figure $5 b$ ). Note that despite the many sources of uncertainty, it is the uncertainty in the climate sensitivity that remains the dominant uncertainty throughout all our calculations.

The results of the probability analyses using the probabilistic forcing distribution are summarized in Table 2. As a check on our models, we have also calculated the results over the period 1880-1990. The estimated temperature change over this period coincides well with the independent estimates from observed temperatures with (coincidentally) similar error bars. Also, our sea level rise estimates agree well with the independent estimates from tide gauge data.

The rtsults of our probabilistic assessment should be used only with caution. They are clearly dependent on the subjective though informed prolsability bounds we have assigned to the uncertainty ranges of the input parameters, and other factors not considered may influence the outcome. As a measure of the uncertainty about the best guess value the results are probably fairly robust but uncertainty in the tails of the distributions is clearly much greater and they cannot yet be used as a reliable guide to assessing the probability of temperature or sea level rise exceeding a certain value. 
a
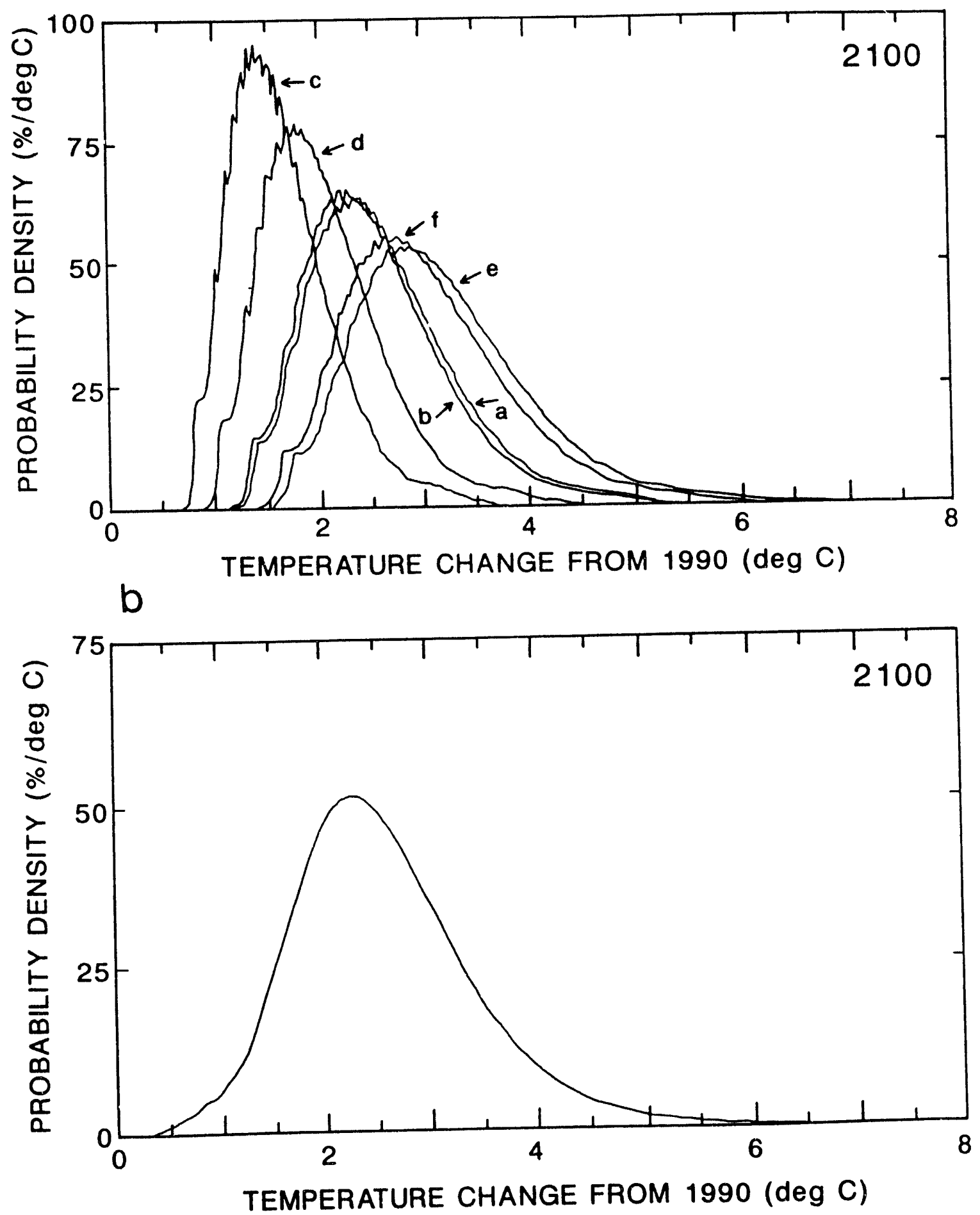

Figure 4: Probabilistic projections of global-mean temperature change over 1900-2100. Uncertainties in the gas cycle models are not included. The emissions scenarios are those of IS92 and correspond to an "existing policies" assumption so new and stronger controls on emissions would shift the probability distributions to the left. The forcing is as given in Wigley and Raper (1992). a) shows the results for the IS92 scenarios a-e, b) shows results using a forcing probability distribution based on scenarios $a, c$ and $e$. 
a
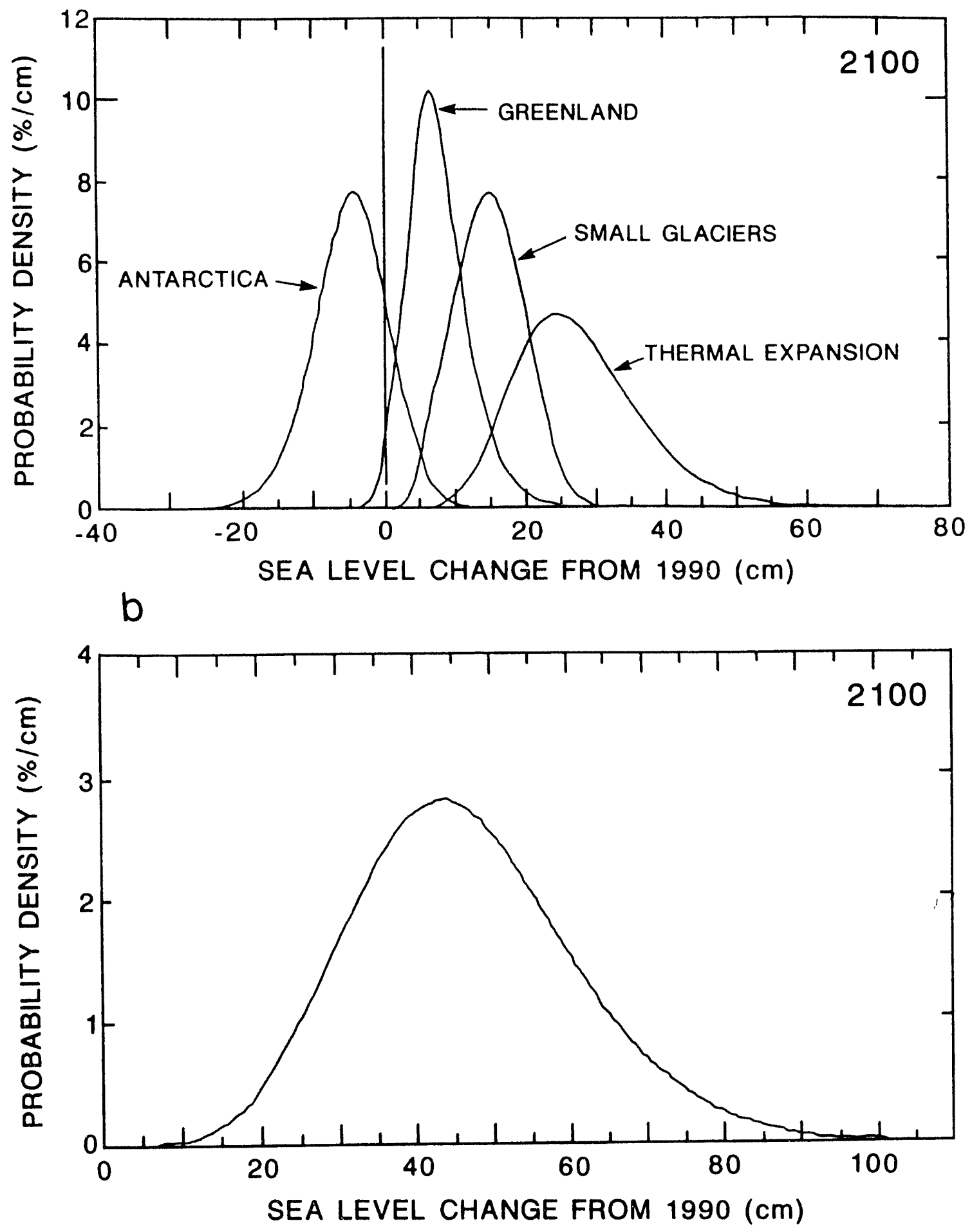

Figure 5: Probabilistic projections of global mean sea level rise over 1900-2100. The forcing is the same as that in Figure $4 \mathrm{~b}$. a) shows the contributions from thermal expansion, small glaciers, Greenland and Antarctica, b) shows the corresponding total sea level rise. 
Table 2: Confidence intervals for temperature and sea level change

\begin{tabular}{lrrrrr}
\hline Cum. Prob. & 0.005 & 0.05 & 0.50 & 0.95 & 0.995 \\
Variable* & & & & & \\
\hline & & & & & \\
\hline & & & & & \\
$\Delta T(1880-1990)$ & 0.24 & 0.29 & 0.42 & 0.63 & 0.79 \\
ditto observed & & 0.30 & 0.45 & 0.60 & \\
$\Delta T(1990-2030)$ & 0.39 & 0.48 & 0.73 & 1.11 & 1.40 \\
$\Delta T(1990-2100)$ & 0.71 & 1.30 & 2.45 & 4.08 & 5.37 \\
$\Delta m s 1(1880-1990)$ & -1.1 & 2.9 & 10.7 & 19.2 & 24.3 \\
$\Delta \mathrm{msl}(1990-2030)$ & 4.8 & 7.3 & 12.7 & 19.3 & 23.3 \\
$\Delta \mathrm{msl}(1990-2100)$ & 15.4 & 24.7 & 45.7 & 72.4 & 88.7 \\
& & & & & \\
\hline
\end{tabular}

${ }^{*} \Delta \mathrm{T}$ in ${ }^{\circ} \mathrm{C}, \Delta \mathrm{ms} 1$ in $\mathrm{cm}$.

Improved Ice Melt Model

Work has continued on the improved ice melt model reported on in FY $92 / 93$. The model equation can be written in the form

$$
\frac{d Y}{d t}=\frac{Y_{e q}-Y}{\tau}
$$

where $\mathrm{Y}=\mathrm{V} \mathrm{n} / \mathrm{m}$ and $\mathrm{Y}_{\mathrm{eq}}=\mathrm{V}_{\mathrm{eq}} \mathrm{n} / \mathrm{m}$ and $\mathrm{V}_{\mathrm{eq}}$ is the temperature-dependent equilibrium value of the volume, $V$, and $\tau$ is a variable glacier response time. The parameters $m$ and $n$ are constants which determine the shape of the glacier. The large sensitivity of equilibrium volume $\left(V_{e q}\right)$ to temperature and long response time $(\tau)$ obtai zed when fitting the model to Storglaciaren, a small glacier in northern Sweden, are controversial.

We can show that our response time is a more general form of the response time put forward by Johannesson et al. (1989). Making a number of additional assumptions we have derived an expression for $\tau$ which is similar to Johannesson et al.'s but which includes shape parameters not considered by them. The assumptions are that the glacier is in equilibrium, and is parallel-sided with uniform surface slope. Under these assumptions our expression for $\tau$ reduces to

$$
\tau_{\text {eq }}=\frac{m}{n} \frac{H}{-B_{T}}
$$

where the parameters $m$ and $n$ are constants which define the changing shape of the glacier with changing volume, $H$ is the mean depth of the glacier and $\mathrm{BT}$ is the mass balance at the terminus.

It is the extra term $\mathrm{m} / \mathrm{n}$ which makes our estimates of the response time longer than Johannesson et al.'s. When $m$ and $n$ are unity, as 
effectively assumed by Johannesson et al., the glacier width and depth are unchanging with changing glacier volume. In other words the addition or subtraction of volume all occurs at the terminus. This ignores the mass-balance elevation feedback and the effect of changing glacier width. Our equation says that if the width increases with increasing volume $(m>1)$ and/or if the depth increases with increasing volume $(n<1)$ the response time will be longer. Johannesson et al. do themselves admit that the mass-balance elevation feedback would tend to increase the response time. A suitable value for $\mathrm{n}$ is about 0.7 , but $\mathrm{m}$ is more difficult to determine.

We have retuned the glacier model using this value of $\mathrm{n}$ with data from 1946-1992 (previously 1946-1980 only). Values of $m$ of 1.0, 2.0, $3.0,4.0$ lead to estimates of $\tau_{\text {eq }}$ at its present volume of $154,171,210$ and 237 years respectively. The best fit to the data is obtained when $\mathrm{m}=4.0$ and $r_{\mathrm{eq}}=237$, as found before, but lower values of $\mathrm{m}$ may be more appropriate. Even so, our estimates of $\tau$ are substantially higher than the generally accepted values.

Another matter of concern is the amount of glacier melt which has occurred over the last century. Recent estimates by Oerlemans and Fortuin (1992) using an energy balance model and results of work carried out in the Climatic Research Unit using a degree day model are in the range $6-12 \mathrm{~mm}$ sea level rise over 1900-1961. This is much less than the original estimate made by Meier (1984) of $28 \mathrm{~mm}$ on which our sea level rise projections are presently based.

In Oerlemans and Fortuin (1992) the temperature sensitivity of the 100 glacier regions considered is derived from a logarithmic relationship between annual precipitation and mass balance which is based on only a small subset of glaciers. Also, whereas Oerlemans and Fortuin consider only a step increase in global mean tenperature, we have used actual regional temperature changes (22 regions), based on station data, as input to the degree day model. As a result, although the two methods agree as to the global mean melt, the contributions from the different glacier regions are not the same.

Neither of the above two analyses include the mass-balance elevation feedback, the importance of which is now becoming more widely recognized. Consideration of the mass-balance elevation feedback would certainly tend to increase the two most recent melt estimates, but just how far it would go to reconciliation with the results of Meier (1984) is still uncertain and a matter for ongoing research.

Whatever the outcome of the above-mentioned problems and/or our final choice of model parameter values, we still consider the glacier melt model which we have developed as ideally suited to estimating future contributions to sea level rise either on a global mean or regional scale.

\section{C3. Coupled climate/carbon cycle modelling}

The primary product in this section of our work is the paper published in Tellus (Wigley, 1993) (Appendix D). This paper describes a simple carbon cycle model based on a convolution ocean component following Maier-Reimer and Hasselmann (1987) and described in Wigley (1991), and a four-box terrestrial component similar to one of the hierarchy described in Harvey (1989). The model has unusual flexibility 
in that it allows the contemporary carbon budget to be balanced in a variety of ways by changing the efficiency of ocean uptake and/or the strength of the $\mathrm{CO}_{2}$ fertilization effect. In Wigley (1993), the model was used to estimate future $\mathrm{CO}_{2}$ concentration changes in response to the IPCC92 emission scenario, and their uncertainties. This is the most comprehensive study of its kind.

In our original proposal we stated our intention to produce a coupled climate/carbon cycle model. This has been done by combining the carbon cycle model with our upwelling-diffusion energy balance climate model (Wigley and Raper, 1987, 1992, 1993) (and with other gas cycle models) in a piece of user-friendly interactive software called MAGICC (Model for Assessing Greenhouse-gas Induced Climate Change). MAGICC includes a new reduced-form model for methane (Osborn and Wigley, 1994) also produced as part of the present project - see Appendix E. The gas cycle models and the climate model run simultaneously allowing feedback effects to be calculated. The carbon cycle model has four temperaturedependent terms affecting gross primary productivity, and plant, litter and soil respiration/decomposition rates. We have yet to carry out any extensive simulations with this model.

The carbon cycle model may also be run in inverse mode, and an extensive set of calculations has been performed to estimate the industrial emissions required to stabilize $\mathrm{CO}_{2}$ concentrations at various levels. These analyses were integrated with an IPCC-sponsored exercise, set up and administered by Wigley and I.G. Enting (CSIRO, Australia), in which many modelling groups were asked to perform a standard set of inverse "stabilization" calculations. The results of this project are summarized in the forthcoming 1994 IPCC report's carbon cycle chapter (Schimel et al., 1994; Wigley is a co-author), and full details will appear later in a CSIRO report (Enting. Wigley and Heimann, in prep.).

C4. Inverse climate and sea level modelling

We have applied the inverse algorithm developed previously (Wigley, 1991) to our climate and sea level models. We can now run these models in inverse mode and determine, for example, the radiative forcing required to produce any specified time series of past and/or future temperature and/or sea level change. When applied to past global-mean temperature changes, the inverse model gives a range of possible forcing histories, corresponding to a range of possible values of $\Delta T_{2 x}$. Comparison with the estimated history of greenhouse and sulphate forcings allows us to estimate a best fit $\Delta \mathrm{T}_{2 \mathrm{x}}$ by minimizing forcing residuals rather than temperature residuals. Preliminary results show some important differences, with the forcing residual method leading to larger implied $\Delta \mathrm{T}_{2 \mathrm{x}}$ values.

We have deferred further work on inverse modelling pending the inclusion of recent and planned improvements in the models.

C5. UD-GCM Comparison

Published results from the MPI O/AGCM (ECHAM-1/LSG) transient run representing IPCC 1990 scenario A show lower sea level rise due to thermal expansion than the IPCC estimates which were carried out with our UD-model, even after correction for the "cold start" depression 
(Cubasch et al., 1992, Hasselmann et al. 1993). We have investigated the reason for this disparity using GCM data supplied by MPI and running our UD-model with the same "cold start" forcing to allow a direct comparison.

We have found that the differences in the thermal expansion are due to relatively less ocean warming in the MPI model compared to the UD-model. This may be largely accounted for by differences in the climate sensitivities of the two models and/or by changes in the thermohaline circulation in the MPI model. In the first instance, we have investigated the possible effect of different climate sensitivities alone. The IPCC best guess for the global mean climate sensitivity of $2.5^{\circ} \mathrm{C}$ was used for the IPCC UD-model estimate, whereas the sensitivities of the MPI model are unknown. The differences in the climate sensitivities might not be only in the global mean sensitivity but also in the land/ocean relative sensitivities. Different land/ocean sensitivities could account for the the ocean warming being much less than the land in the MPI model. Different land/ocean sensitivities have also been noted by Murphy (1994) in the U.K. Met. Office A/OGCM.

First, we have compared the MPI results with the best guess UDmodel results and with tuned UD-model results. For the latter we tuned the UD-model to fit the global mean temperature and expansion of the MPI model by adjusting the global mean climate sensitivity $\Delta \mathrm{T}_{2 \mathrm{x}}$, the diffusivity $K$ and the sinking water temperature parameter $\pi$. A reasonably good fit is obtained when $\Delta \mathrm{T}_{2 \mathrm{x}}=1.8^{\circ} \mathrm{C}, \mathrm{K}=0.6 \mathrm{cms}^{-1}$ and $\pi=0.1$.

The MPI results can be expressed either as anomalies from the first decade of the control run (denoted Definition 1) or as anomalies from the corresponding year in the control run (denoted Definition 2). Differences arise because of climate drift in the control run.

The global mean temperature profiles for 2100 in Figure 6 show that there is much greater warming of the top $1000 \mathrm{~m}$ with the best guess UD-model parameters $\left(\Delta \mathrm{T}_{2 \mathrm{x}}=2.5^{\circ} \mathrm{C}, \mathrm{K}=1.0 \mathrm{cms}^{-1}\right.$ and $\pi=0.2$ (IPCC used $\pi$ $=1.0)$ ) compared with the MPI profiles for Definition 1 and 2 (as defined above). Even after tuning the global mean temperature and expansion it is clear that the UD-model ocean surface warming is still much greater than the MPI results.

This is clearly an artefact of the different warming rates over land and ocean in the GCM - given this, tuning to the global-mean will overestimate the surface ocean warming. We have therefore retuned the UD-model so that the temperature profile is in good agreement with the MPI results by using different climate sensitivities for the land and ocean; namely $\Delta \mathrm{T}_{2 \mathrm{x}}$ land $\sim 3.7^{\circ} \mathrm{C}$ and $\Delta \mathrm{T}_{2 \mathrm{x}}$ ocean $\sim 1.4^{\circ} \mathrm{C}$. These values give a global mean sensitivity of $\Delta \mathrm{T}_{2 \mathrm{x}}=2.1^{\circ} \mathrm{C}$. Note that the latter is higher than the first estimate of $1.8^{\circ} \mathrm{C}$ arrived at by tuning the global mean values only. This apparent differential in the land/ocean climate sensitivity has important implications not only for thermal expansion but also for the global mean climate sensitivity as well as regional temperature changes. We plan to expand on this work in the next contract by including the effect of changes in the thermohaline circulation. We expect this to reduce the required land/ocean climate sensitivity differential. 


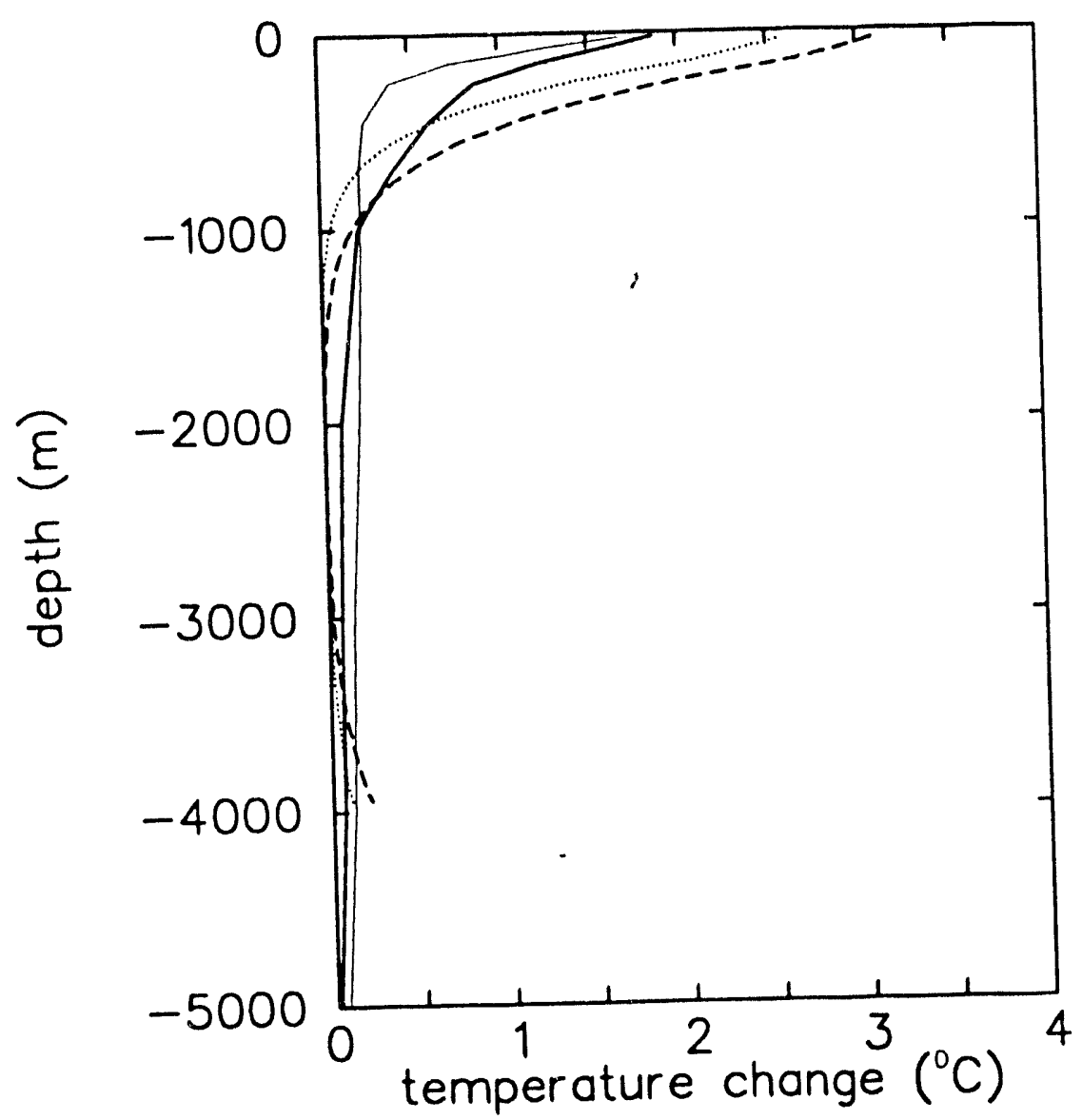

Figure 6: Ocean mean temperature change profiles for the year 2100 using IPCC 1990 scenario A cold start forcing as defined by MPI for a) the MPI GCM (ECHAM-1/LSG) Definition 1 ( 2100 anomaly from the first decade of the control run) - thin solid b) the MPI Definition 2 ( 2100 anomaly from the 2100 control) - thick solid c) the UD-model with best guess model parameters - dashed and d) the UD-model with $\Delta \mathrm{T}_{2 \mathrm{x}}=1.8$, $\mathrm{K}=0.6 \mathrm{~cm} \mathrm{~s}-1, \pi=0.1$ - dotted. 
In Wigley and Raper (1992), we considered the aerosol contribution to future radiative forcing in giving projections of global-mean temperature and sea level rise in response to the IPCC 92 emissions scenarios (see Appendix F). Our climate model differentiates land and ocean in both hemispheres, and the aerosol forcing was similarly split (albiet somewhat arbitrarily). The forcing was divided into direct (clear sky) and indirect (cloud albedo) effects, with the former dominating. Uncertainties were also considered, based on a best guess $\Delta Q(\mathrm{global})=-0.75 \mathrm{Wm}^{-2}$ in 1990 and using $\pm 50 \mathrm{z}$ as the uncertainty range. These values are consistent with the latest $a$ priori IPCC estimates, which give a range of $-0.3 \mathrm{Wm}-2^{2}$ to $-3.0 \mathrm{Wm}^{-2}$. We believe values much above $-1.5 \mathrm{Wm}-2^{2}$ to be unlikely because they would probably have caused more noticeable climate effects than anything observed to date although we note that this opinion is far from being universally shared. The temperature and sea level projections we published in 1992 are still the only ones available in which an attempt was made to consider all of the primary anthropogenic forcing factors. We also produced a review of the climatic effects of sulphate aerosols (Charlson and Wigley, 1994) (Appendix G).

We originally proposed to carry out a more detailed assessment of the effect of aerosol forcing on the relative warming rates of the Northern and Southern Hemispheres. While our model gives this information, we consider interpretation of these results premature. This is because other factors, still poorly understood and difficult to quantify, may also lead to interhemispheric temperature contrasts that would likely obfuscate the aerosol effect.

To elaborate, recent transient O/AGCM results show more rapid warming over land than over ocean (see $C 5$ ). This yields a more rapid warming in the Northern Hemisphere, which would tend to offset any aerosol-induced differential. To properly model these two competing effects requires further development work, even at the simple level of modelling that we have been using. The issue is further complicated by the possibility of a differential sensitivity effect, with aerosol sensitivity $\left(\Delta \mathrm{T}_{\text {equil }} / \Delta Q\right.$ ) being less than $\mathrm{CO}_{2}$ sensitivity (Taylor and Penner, 1994). We plan to investigate these aspects further in our next proposal.

\section{C7. Low-frequency climate variability}

Both passive variability (i.e., arising from ocean thermal inertia) and active variability (i.e., through variations in the ocean circulation and its interaction with the atmosphere) could be significant sources of low-frequency climate variability. Our work on passive variability involving the application of our generalized 1-D upwelling-diffusion models in the frequency-domain, has been described in section $C 1$. Our investigations of active oceanic variability are described below.

Variability of the ocean circulation is believed to occur over a wide range of timescales, and could affect surface climate through changes in heat transport, changes in convection and subsequent heat release to the atmosphere, and changes in the depth of the surface mixed layer. The broad range of timescales involved currently precludes the use of coupled A/OGCMs to fully investigate such possibilities 
(including the parameter and resolution sensitivity of any variability obtained), although improved computer resources now allow some preliminary A/OGCM investigations to be made (e.g.. Delworth et al.. 1993). For the longer timescales, and for more exhaustive investigations, OGCMs that are not coupled to AGCMs must be used, forced by climatological atmospheric conditions, together with some kind of simplified representation of changes in the atmosphere.

Some kind of hierarchy of representations of atmospheric anomalies can be envisaged, beginning with completely random and spatially incoherent anomalies; then, anomalies that have similar spatial patterns to those observed; then, anomalies that are predicted empirically from the OGCM's surface variables (i.e., active atmospheric feedback is included), using a statistical model constructed from observed data; then, a two dimensional energy-balance atmosphere. Such a hierarchy leads eventually to a fully coupled A/OGCM, but with the advantages of being less computationally expensive and of being able to identify key processes as the complexity is gradually increased. Ideally, such a hierarchy should be performed using a range of OGCMs.

The first and second steps in the hierarchy have already been investigated for the Hamburg LSG OGCM (Maier-Reimer and Hasselmann, 1987 ) by Mikolajewicz and Maier-Reimer (1990) and by Barnett et al. (1994). The LSG model was forced by climatological mixed boundary conditions, with the addition of a stochastic fresh-water flux at the surface. Significant variability was discovered in that model, so it is important to see if such variability (or any new oscillation) is present in other OGCMs. We have performed an identical experiment, but with the OPYC OGCM (Oberhuber, 1993), in collaboration with $\mathrm{Dr}$. J. Oberhuber and Dr. T. Barnett.

The usefulness of the first results is less than expected, at least for climatological applications. This is due to the occurrence of a few events involving massive freshening of the upper ocean, particularly at a number of coastal grid-points. From our analysis of the model's results, it does not appear that these events can be explained by the model's dynamics and physics. This indicates that there may be a numerical problem with the OPYC model - although it may not be a fundamental problem, since a pathological combination of timestep, resolution and grid layout has not been eliminated as the cause. Further, we have performed many sensitivity studies with the OPYC model which indicate that it is highly sensitive to changes in its physical parameterisations. So, it is possible that some small alteration to the physics of this model may prevent these apparently unrealistic events from re-occurring. If 80 , then we have yet to find the necessary alteration. A final possibility is that the problem lies with the CONVEX computer on which the model was integrated ( $\mathrm{J}$. Oberhuber, personal communication).

These massive freshening events dominate other variability that occurred within the experiment. Concurrent sensitivity studies with OPYC had highlighted a deficiency in the parameterisation of convection, and this was reflected in the poor simulation of the present-day water mass distribution in the variability experiment. This deficiency has now been improved. The OPYC model is in a continuous state of development, and numerous improvements have been made over the past 18 months. At present, the variability experiment is being repeated, using the latest version of OPYC, at a higher resolution, and on a different computer - it is hoped that these differences will yleld improved results. Analysis of these new results is proceeding at present. 


\section{GCM Validation}

As new GCMs are developed, increasingly coupled with ocean models, there is a continuing need for validation using high quality data bases and suitable statistical procedures. Our dataset development work (see section $A$ here and previous reports) is not fust to provide climatologies but also gridded time series to undertake statistical significance testing using appropriate software (Wigley and Santer, 1990).

During the present study we have extended the precipitation validation study of Hulme (1991). This study looked at the monthly pattern correlations between two observed precipitation climatologies (Legates and Willmott (1990) which is global having precipitation estimates over oceanic, as well as land, regions and a land-only climatology developed by Hulme (1992)) and nine GCM precipitation climatologies. The land-only precipitation is an improved (more stations) and updated (new reference period 1961-90) version of Hulme (1992). Some of the improvements have been achieved by finding precipitation data with the temperature data found in section $A$.

The new study looks at three more GCM climatologies than Hulme (1991) and considers two sub-domains of the globe: Europe $\left(35^{\circ}\right.$ to $70^{\circ} \mathrm{N}$ by $15^{\circ} \mathrm{W}$ to $\left.45^{\circ} \mathrm{E}\right)$ and North America $\left(25^{\circ}\right.$ to $55^{\circ} \mathrm{N}$ by $65^{\circ}$ to $\left.125^{\circ} \mathrm{W}\right)$. The results are displayed in Figures 7 to 9 . In addition to showing the results of nine models, two GCM composite curves are shown which are the weighted and unweighted averages of the nine model precipitation fields. In the weighted composite, more weight is given to models that correlate better with the observed precipitation climatologies. The averaging is only done globally so the regional composites are merely subsets of the global composites. 
Correlation between global land \& oceon precip. fields with respect to: LEGATES \& WILLMOTT, uncorrected $(n=2592)$

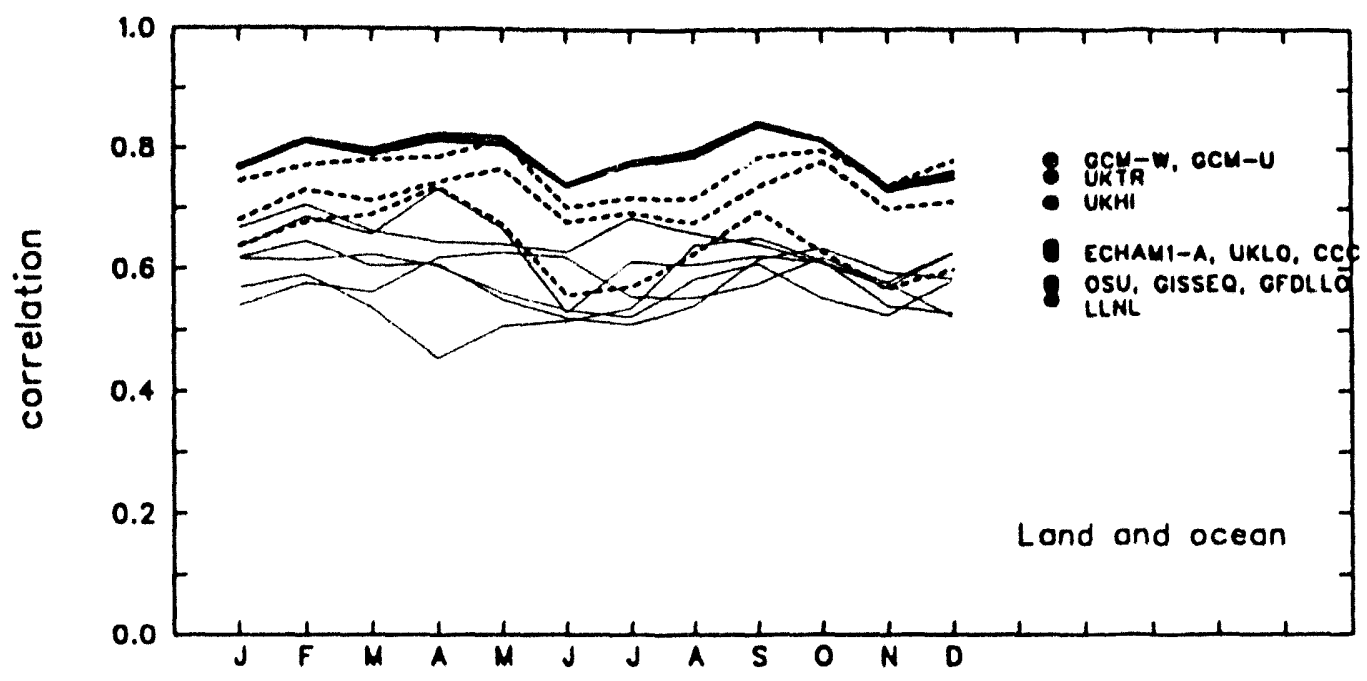

Correlation between global land precip. fields with respect to: CRU6190 $(n=700)$

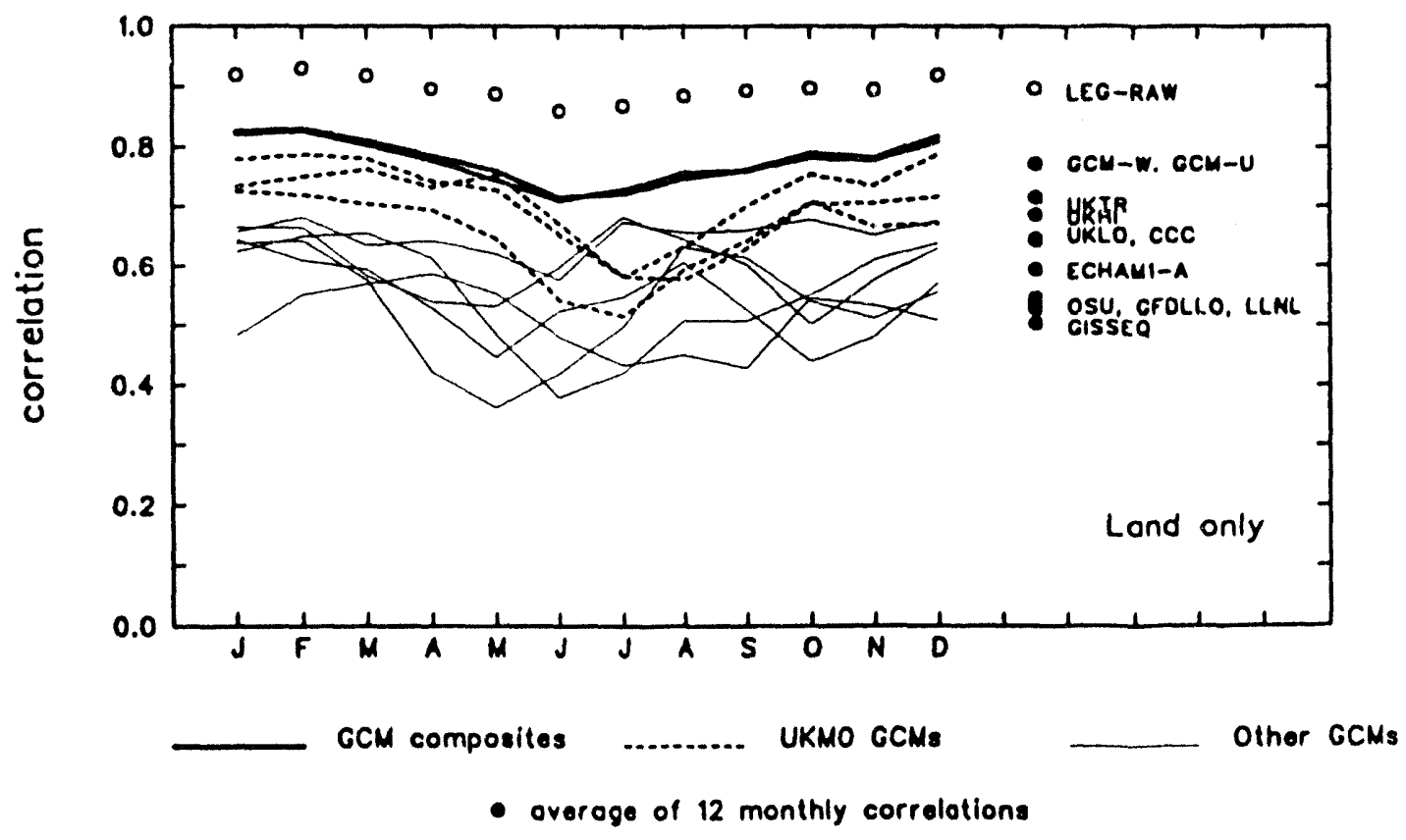

Figure 7: Monthly pattern correlations between observed (LEGATES and WILLMOTT) and modelled land and ocean precipitation (top) and observed (CRU6190) and modelled land-only precipitation (bottom). Dots on the right hand side indicate the average of the 12 monthly correlations. The three new models (control runs) are CCC (Canadian Climate Centre), UKTR (Hadley Centre Transient), ECHAMI-A (Max Planck Institute, Large Scale Geostrophic Model), GCM-W and GCM-U represent the weighted and unweighted model composites. On the lower plot, the pattern correlations between the two climatologies are shown over land areas (2592 $5 \times 5^{\circ}$ squares of which 700 are available as in the CRU6190 climatology). 
Correlation between European land \& ocean precip. fields with respect to: LEGATES \& WILLMOTT, uncorrected $(n=84)$

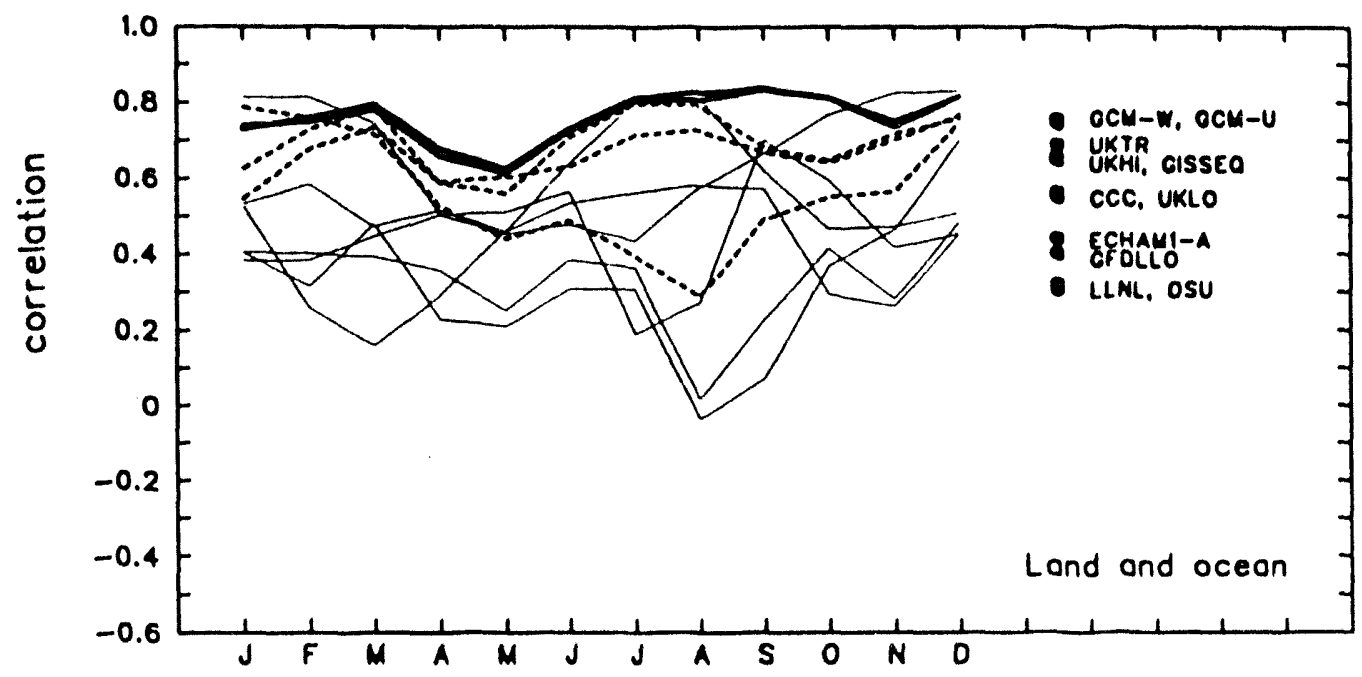

Correlation between European land precip. fields with respect to: CRU6190 $(n=71)$

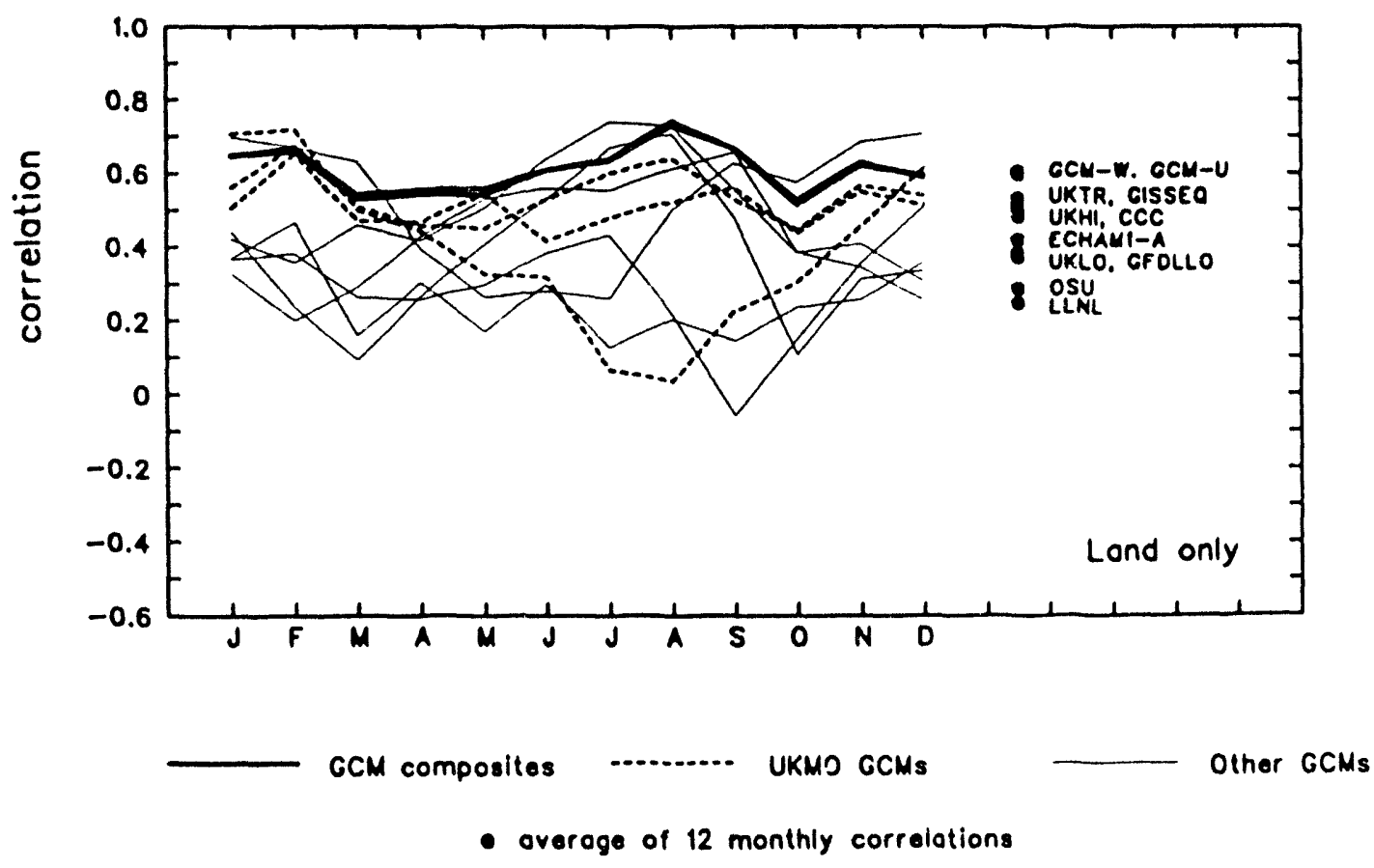

Figure 8: As Figure 7, only for Europe ( $845 \times 5^{\circ}$ squares of which 71 are considered land). 
Correlation between N.American land \& ocean precip. fields with respect to: LEGATES \& WILLMOTT, uncorrected $(n=72)$

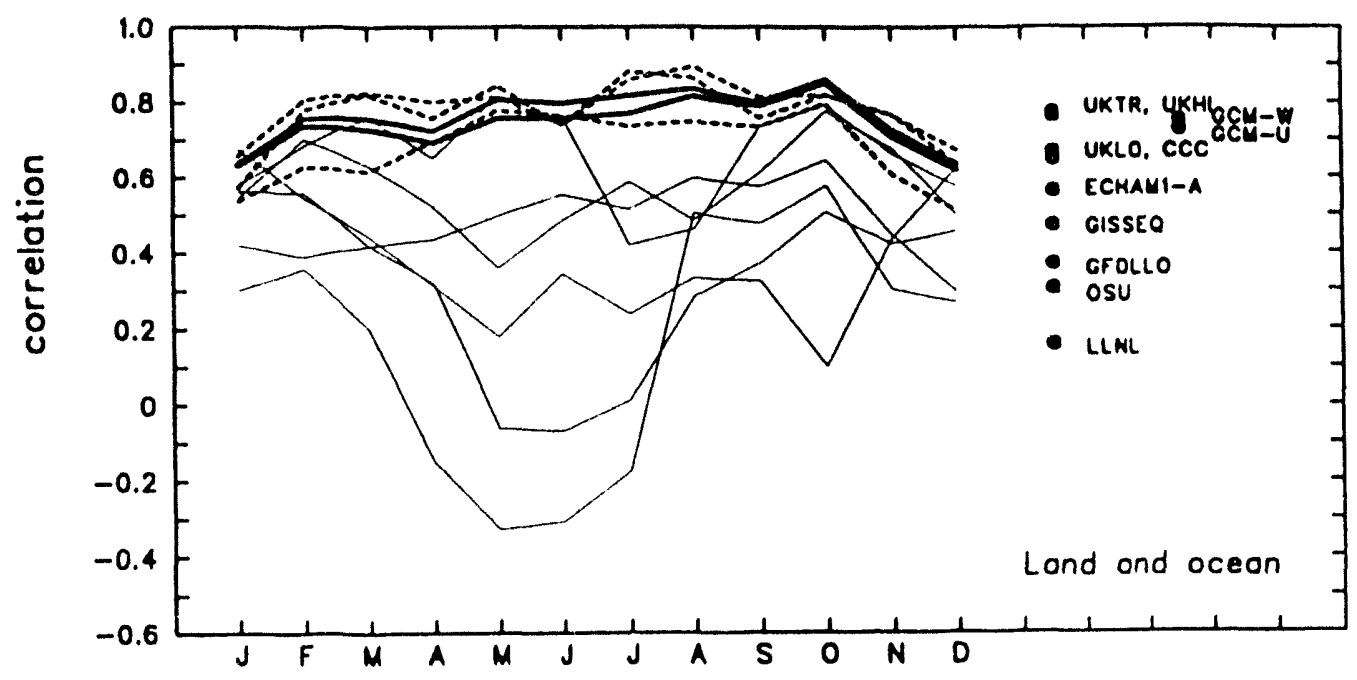

Correlation between N.American land precip. fields with respect to: CRU6190 $(n=63)$

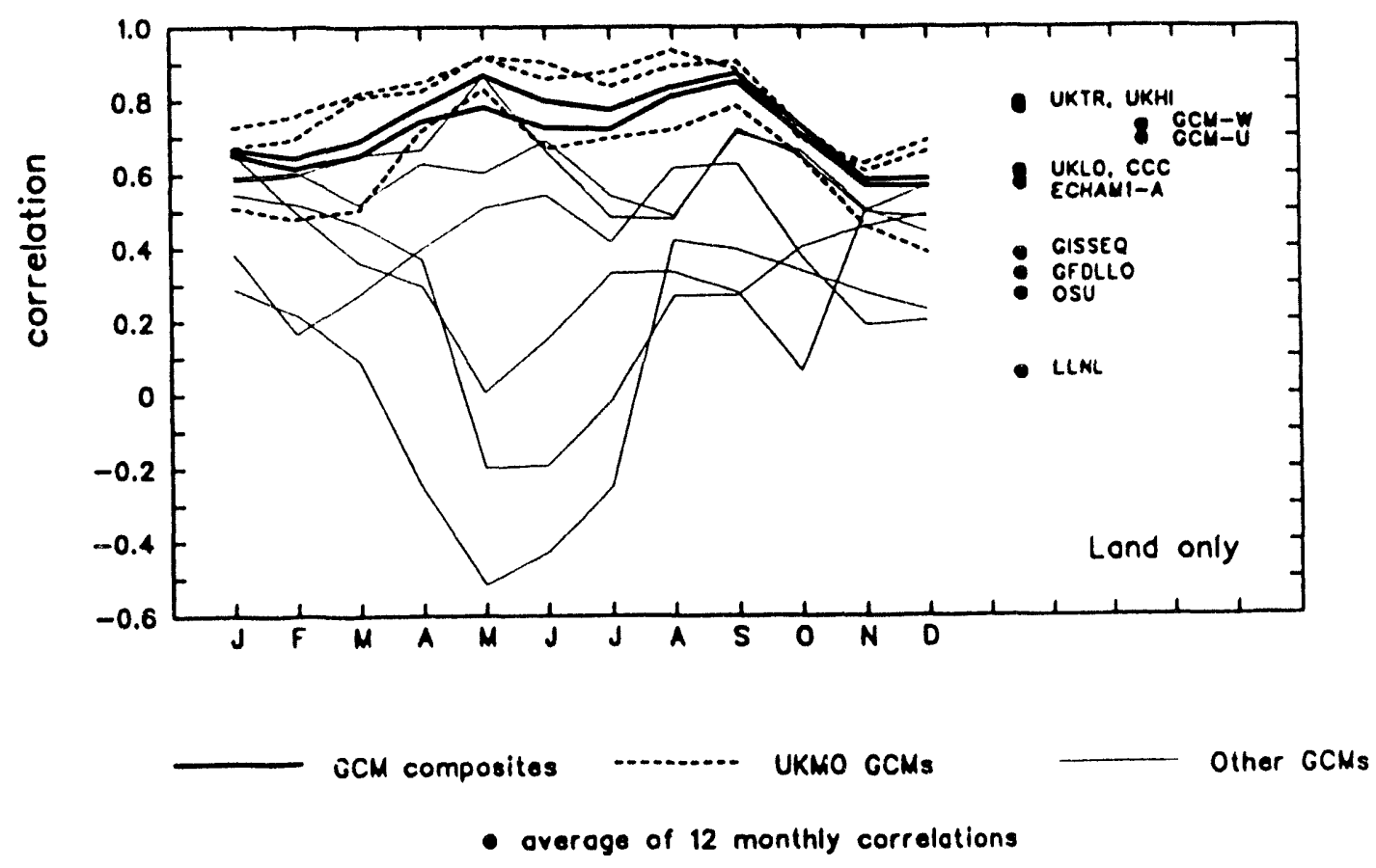

Figure 9: As Figure 7, only for North America $\left(725 \times 5^{\circ}\right.$ squares of which 63 are considered land). 


\section{E. References}

Angell, J.K., 1988: Variations and trends in tropospheric and stratospheric global temperatures, 1958-87. Journal of Climate 1, 12961313.

Barnett, T.P., 1986: Detection of changes in global tropospheric temperature fields induced by greenhouse gases. Journal of Geophysical Research 91, 6659-6667.

Barnett, T.P. and Schlesinger, M.E., 1987: Detecting changes in global climate induced by greenhouse gases. Journal of Geophysical Research 92, $14772-14780$.

Barnett, T.P., Chu, M., Wilde, R., Mikolajewicz, U., 1994: Low frequency ocean variability induced by stochastic forcing of various colours. Proceedings of National Research Council Workshop on decadeto-century time scales of climate variability, Irvine, California, 21-25 Sept. 1992.

Bradley, R.S., Ahern, L.G. and Keimig, F.T., 1994: A computer-based Atlas of global instrumental climate data. Bulletin of the American Meteorological Society 75, 35-41.

Briffa, K.R. and Jones, P.D., 1993: Global surface air temperature variations during the twentieth century: Part 2, Implications for largescale high-frequency paleoclimatic studies. The Holocene 3, 77-88.

Charlson, R.J. and Wigley, T.M.L., 1994: Sulfate aerosol and climatic change. Scientific American 270, No. 2, 28-35.

Christy, J.R. and McNider, R.T., 1994: Satellite greenhouse signal. Nature 367,325 .

Christy, J.R. and Wigley, T.M.L., 1994: Sulfate aerosol and climatic change. Scientific American 270, 28-35.

Cubasch, U., Hasselmann, K., Hock, H., Maier-Reimer, E. Mikolajewicz, U., Santer, B.D. and Sausen, R., 1992: Time-dependent greenhouse warming computations with a coupled ocean-atmosphere model. Climate Dynamics 8, 55-69.

Delworth, T., Manabe, S. and Stouffer, R.J., 1993: Interdecadal variations of the thermohaline circulation in a coupled ocean-atmosphere model. $J$. of Climate 6, 1993-2011.

Folland, C.K., Karl, T.R. and Vinnikov, K. Ya., 1990: Observed climate variations and change. In Climate Change: The IPCC Scientific Assessment (J.T. Houghton, G.J. Jenkins and J.J. Ephraums, Eds.) Cambridge University Press, 195-238.

Folland, C.K., Karl, T.R., Nicholls, N., Nyenzi, B.S., Parker, D.E. and Vinnikov, K.Ya., 1992: Observed climate variability and change. In, Climate Change 1992: The Supplementary Report to the IPCC Scientific Assessment (J.T. Houghton, B.A. Callander and S.K. Varney, Eds.), Cambridge University Press, pp. 135-170.

Folland, C.K., Reynolds, R.W., Gordon, M. and Parker, D.E., 1993: A study of six operational sea surface temeprature analyses. Journal of Climate 6, 96-113. 
Gargett, A.E., 1984: Vertical eddy diffusivity in the ocean interior. J. Mar. Res. 42, 359-393.

Graf, H-F., Kirchner, I., Robock, A. and Schult, I., 1993: Pinatubo eruption winter climate effects: model versus observations. Climate Dynamics 9, 81-93.

Hahn, C., Warren, S.G., London, J., Jenne, R.L. and Chevin, R.M., 1994: Updated version of 'Climatological data for cloud cover over the globe from surface observations'. NDP-026, CDIAC, Oak Ridge, In.

Harvey, L.D.D., 1990: Effect of model structure on the response of terrestrial biosphere models to $\mathrm{CO}_{2}$ and temperature increases. Global Biogeochemical Cycles 4, 137-153.

Hasselmann, K., Sausen, R., Maier-Reimer, E. and Voss, R., 1993: On the cold start problem in transient simulations with coupled amosphericocean models. Climate Dynamics 9, 53-61.

Hoffert, M.I. and Flannery, B.P., 1985: Model projections of the timedependent response to increasing carbon dioxide. In, Projecting the climatic effects of increasing carbon dioxide (eds. M.C. Maccracken and F.M. Luther), US Department of Energy, Carbon Dioxide Research Division, Washington DC, 149-190.

Hulme, M., 1991: An intercomparison of model and observed global precipitation climatologies. Geophysical Research Letters 18, 17151718 .

Hulme, M., 1992: A 1951-80 land-based global precipitation climatology for the evaluation of General Circulation Models. Climate Dynamics 7 , $57-72$.

Johannesson, T., Raymond, C. and Waddington, E., 1989: Time-scale for adjustment of glaciers to changes in mass balance. Journal of Glaciology 35(121), 355-369.

Jones, P.D., 1991: Southern Hemisphere sea level pressure data: an analysis and reconstructions back to 1951 and 1911. International Journal of Climatology 11, 585-607.

Jones, P.D., 1994a: Observations from the surface - projections from traditional meteorological observations. In, Future Climates of the World, World Survey of Climatology (A. Henderson-Sellers, Ed.) Elsvier (in press).

Jones, P.D., 1994b: Recent warming in global temperature series. Geophysical Research Letters (in press).

Jones, P.D., 1994c: Maximum and minimum temperature trends in Ireland, Italy, Thailand, Turkey and Bangladesh. In Asymmetric Change of Daily Temperature, Proceedings of the International Minimax Workshop ( $G$. Kukla, T.R. Karl and M.R. Riches, Eds.) Department of Energy Conference Series, 113-126.

Jones, P.D., Raper, S.C.B., Bradley, R.S., Diaz, H.F., Kelly, P.M. and Wigley, T.M.L., 1986a: Northern Hemisphere surface air temperature variations, 1851-1984. Journal of Climate and Applied Meteorology 25, 161-179. 
Jones, P.D., Raper, S.C.B. and Wigley, T.M.L., 1986b: Southern Hemisphere surface air temperature variations, 1851-1984. Journal of Climate and Applied Meteorology 25, 1213-1230.

Jones,P.D. and Wigley, T.M.L., 1988: Antarctic gridded sea level pressure data: an analysis and reconstruction back to 1957 . Journal of Climate 1, 1199-1220.

Jones, P.D. and Wigley, T.M.L., 1990: Satellite data under scrutiny. Nature $344,711$.

Jones, P.D. and Briffa, K.R., 1992: Global surface air temeprature variations: Part I The instrumental period. The Holocene 2, 174-188.

Jones, P.D. and Kelly, P.M., 1994: The effect of large explosive volcanic eruptions on surface air temperature. In Large Volcanic Eruptions (G. Fiocco, Ed.) Accademia Nazionale dei Lincei (in press).

Karl, T.R., Jones, P.D., Knight, R.W., Kukla, G., Plumer, N., Razuvayev, V., Gallo, K.P., Lindesay, J. and Peterson, T.C., 1993: Asymmetric trends of maximum and minimum temperature: empirical evidence and possible causes. Bulletin of the American Meteorological Society 74, 1007-1023.

Kelly, P.M., Jones, P.D., Wigley, T.M.L. and Diaz, H.F., 1994: Recent global warmth moderated by the effects of the Mount Pinatubo eruption. Proc. 18th Climate Diagnostics Workshop (D.R. Rodenhuis, Ed.) U.S. Dept. of Commerce, NOAA, 5-8.

Legates, D.R. and Willmott, C.J., 1990: Mean seasonal and spatial variability in gauge-corrected, global precipitation. International Journal of Climatology 10, 111-128.

Levitus, S., 1982: Climatological atlas of the world ocean. NOAA Prof. Paper No. 13, US Government Printing Office, 173pp.

Maier-Reimer, M.F. and Hasselmann, K., 1987: Transport and storage of $\mathrm{CO}_{2}$ in the ocean - an inorganic ocean-circulation carbon cycle model. Climate Dynamics 2, 63-90.

Meier, M.F., 1984: Contribution of small glaciers to global sea level. Science 226, 1418-1421.

Mikolajewicz, U. and Maier-Reimer, E., 1990: Internal secular variability in an ocean general circulation model. Climate Dynamics 4, 145-156.

Moberg, A. and Alexandersson, H., 1994: Urban bias trend observed in the Swedish part of gridded temperature data. International Journal of Climatology (submitted).

Murphy, J.M.,1994: Transient response of the Hadley Centre coupled ocean-atmosphere model to increasing carbon dioxide. Part III. Analysis of global-mean response using simple models. Climate Dynamics (in press)

Oberhuber, J.M., 1993: Simulation of the Atlantic Circulation with a coupled sea-ice-mixed-layer isopycnal general circulation model. Part I: Model description. J. of Physical Oceanography 23, 808-829. 
Oerlemans, J. and Fortuin, J.P.F., 1992: Sensitivity of glaciers and small ice caps to greenhouse warming. Science 258, 115-117.

Osborn, T.J. and Wigley, T.M.L., 1994: A simple model for estimating methane concentration and lifetime variations. Climate Dynamics 9, 181193.

Pacanowski, R.C. and Philander, S.G.H., 1981: Parameterization of vertical mixing in numerical models of tropical oceans. J. Phys. Oceanogr. 11, 1443-1451.

Parker, D.E., Jones, P.D., Bevan, A. and Folland, C.K., 1994 : Interdecadal changes of surface temperature since the late 19th century. Journal of Geophysical Research (in press).

Salinger, J.M., Basher, R.E., Fitzharris, B.B., Hay, J.E. and Jones, P.D., 1994: Climate trends in the South West Pacific. International Journal of Climatology (in press).

Santer, B.D., Wigley, T.M.L. and Jones, P.D., 1993: Correlation methods in fingerprint detection studies. Climate Dynamics (in press).

Schimel, D.S., Enting, I., Heimann, M., Wigley, T.M.L., Raynaud, D., Alves, D. and Siegenthaler, U., 1994: The carbon cycle. In Radiative Forcing of Climate Change (IPCC Working Group I Report) (in press).

Schlesinger, M.E. and Ramankutty, N., 1994: An oscillation in the global climate system of period 65-70 years. Nature 367, 723-726.

Taylor, K.E. and Penner, J.E., 1994: Anthropogenic sulfate aerosols and climate change, Nature, 369, 734-737.

Trenberth, K.E., Christy, J.R. and Hurrell, J.W., 1992: Monitoring global monthly mean surface temperatures. Journal of Climate 5, 140523.

Wigley, T.M.L. and Raper, S.C.B., 1987: Thermal expansion of sea water associated with global warming. Nature 330, 127-131.

Wigley, T.M.L., 1991: A simple inverse carbon cycle model. Global Biogeochemical Cycles 5, 373-382.

Wigley, T.M.I., 1993: Balancing the carbon budget. Implications for projections of future carbon dioxide concentration changes. Tellus 45B, 409-425.

Wigley, T.M.L., 1994: How important are carbon cycle model uncertainties? In The Rio Convention on Climate Change: The New Regime and the Agenda for Research (Ed. T. Hanisch), Westview Press (in press).

Wigley, T.M.L. and Raper, S.C.B., 1990: Natural variability of the climate system and detection of the greenhouse effect. Nature 344, 324327.

Wigley, T.M.L. and Santer, B.D., 1990: Statistical comparison of spatial fields in model validation, perturbation and sensitivity experiments. Journal of Geophysical Research 95, 851-865. 
Wrigley, T.M.L. and Raper, S.C.B., 1991: Internally generated natural variability of global-mean temperatures. In, Greenhouse-gas-induced climatic change: a critical appraisal of simulations and observations (ed. M.E. Schlesinger), Kluwer Academic Publishers, Dordrecht, 471-482.

Wrigley, T.M.L. and Raper, S.C.B., 1992: Implications for climate and sea level of revised IPCC emissions scenarios. Nature 357, 293-300.

Wrigley, T.M.L. and Raper, S.C.B., 1993: Future changes in global mean temperature and sea level. In, Climate and sea-level change: observation, Projections and Implications (R.A. Warrick, E.M. Barrow and T.M.L. Wiley, Eds.). Cambridge University Press, 111-133.

Reprints + Rneginits Removed.

42 

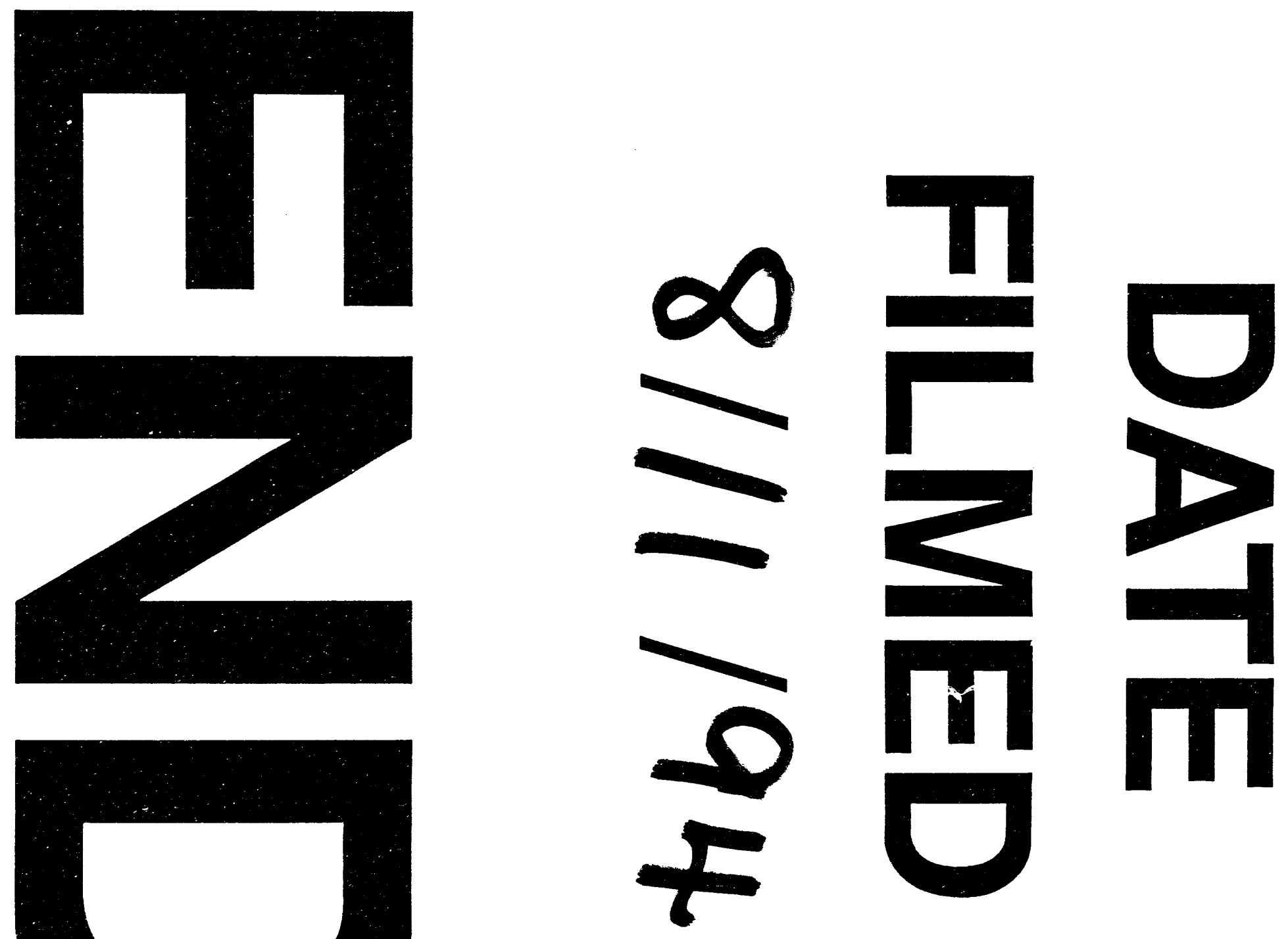
